\title{
A STUDY OF THE PATHOLOGY AND PATHOGENESIS OF BRONCHIECTASIS *
}

BY

\author{
F. WHITWELL \\ From the Departments of Pathology, Broadgrcen and Aintree Hospitals, Liverpool
}

(RECEIVED FOR PUBLICATION FEBRUARY 26, 1952)

Since the first description of bronchiectasis by Laennec in 1819 its pathogenesis has been a controversial topic, and although the many theories have their recurring moments of popularity, none has as yet found general acceptance.

One reason for this lies in the widely varying views of different workers as to the essential nature of the disease. Nowadays the divergence of opinion seems to be occupational, for, while many physicians and radiologists think of the bronchial inflammatory changes as mild and the dilatations of a mechanical nature, most surgeons and pathologists regard bronchiectasis as a destructive inflammatory process.

The pathology of bronchiectasis has been investigated for over a century and the various accounts are conflicting. It has been stated that many tissue changes described in the earlier literature could be attributed to terminal infections and post-mortem autolysis, and that operation specimens show less severe lesions which are more consistent with clinical findings. However, in several recent accounts the pathological changes described have been quite as advanced as those found in postmortem material, 'but such descriptions have been found unacceptable to many clinicians, who regard radiological findings as truer reflections of the underlying pathology. The popular acceptance of this view, with its effect on theories of pathogenesis, has stimulated the present investigation.

It was thought that diversity in the described lesions of bronchiectasis might be explained by one or more of the following suppositions. (1) Histological sections may not have been selected (by different investigators) from comparable areas of lung tissue. (2) Variation of histology is due to the severity, extent, and duration of the illness. (3) Bronchiectasis is not a single pathological entity, but a group of differing conditions having bronchial dilatation as a common factor.

* Based upon part of an M.D. thesis submitted to the University of London in July, 1949.
During a re-examination of histological sections of many bronchiectatic lobes most of the described lesions were seen, but it was impossible to assess their frequency, importance, or inter-relationship, or even to locate them. It was thought that the more important features of the disease were being obscured by detailed histological examination, and that further knowledge might be gained by adopting other methods.

One difficulty in examining such specimens is that dissection of the bronchial tree damages the lung tissue and obscures the original shape of the bronchi. Alternatively, to cut the lobes into parallel slices gives more information about bronchial calibre and peribronchial structures, but less about the bronchial tree as a whole.

In the present investigation the site, shape, and histology of the lesions of bronchiectasis have been studied in 200 consecutive operation specimens by the following methods: (1) preparation from 70 specimens of large histological sections, at varying distances from the hilum; (2) detailed dissection of the bronchial tree of 110 specimens, with histological sections of selected areas; (3) examination of neoprene casts of the bronchial tree from 20 specimens.

The object of this work has been to find out whether any particular types of bronchiectatic lesions are frequently found together, and whether their pathology can be correlated to the patients' age, symptoms, duration of disease, or to the nature of causative illnesses. The first few specimens examined all showed widely differing appearances, and, but for the fact that they had been resected because of clinical bronchiectasis, they would certainly not have been considered as examples of the same pathological condition. When more specimens had been studied it was found that about half of them belonged to one or other of four distinctive types. The remainder of the specimens formed a heterogeneous group, into which were also placed those lobes where the original histology 


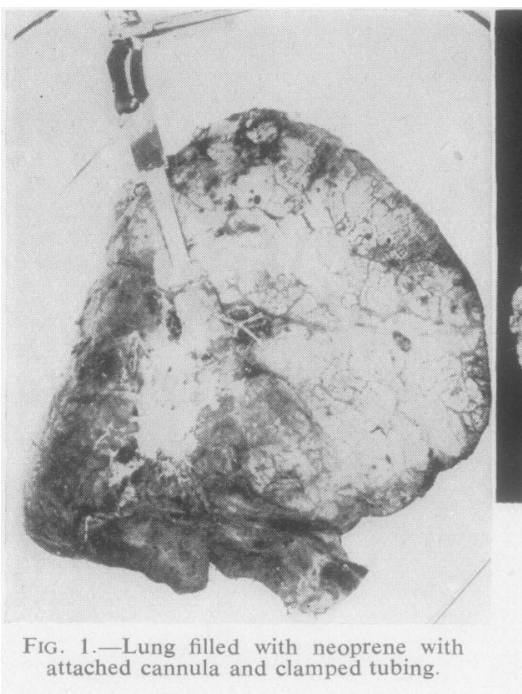

was obscured by the severity of the disease or by secondary changes, and those lobes used for neoprene injections.

A large series of specimens has been examined to provide adequate numbers of each of these common types of bronchiectasis. It was thought that if these were distinct conditions, and not just variations in a single disease, it might be apparent from an examination of the patients' case-notes. When all the specimens had been examined, the essential clinical features of the cases were obtained from the clinical records, and tabulated by. a colleague who was unaware of the pathological classification. These clinical findings have supported the opinion that bronchiectasis really consists of several distinct conditions.

Acceptance of this view assists in explaining not only apparently contradictory accounts of the pathology of bronchiectasis, but also the multiplicity of theories of pathogenesis. These are discussed later.

\section{MATERIAL AND TECHNIQUE OF THE INVESTIGATION}

The material consisted of 200 consecutive operation specimens removed on account of bronchiectasis or cystic disease of the lung at the Surgical Chest Centre, Broadgreen Hospital, Liverpool, during the period 1946-48. Segmental resections were rarely performed during this period, and the specimens were nearly all entire lobes and lungs.

\section{Fixation}

The surgeons fixed the specimens in the operating theatre by low-pressure injection of $5 \%$ formol-saline into the bronchial tree, until the volume of lung tissto corresponded to the observed natural degree of inflation. The specimens were then placed in a large volume of this fixative for at least two weeks. All specimens wers treated in this manner irrespective of the subsequent method of study.

\section{LARGe Sections}

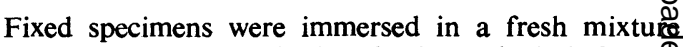
of solid carbon dioxide in absolute alcohol for minutes to freeze them. They were then sawn inter blocks, $1 \mathrm{~cm}$. thick, with an electric bandsaw, the plane of section being roughly at right angles to the lobar bronchi. The blocks were dehydrated in ethy alcohol, cleared in xylol, and embedded in paraffic wax, the entire process being carried out at reduceuf pressure $(500 \mathrm{~mm}$. Hg.).

Sections $10 \mu$ thick were cut and samples from eack block stained and examined. In many cases seria sections were taken from the hilum to the periphery. and every fiftieth one was examined. The stains used on every specimen were Mayer's haemalum and eosin Weigert's haematoxylin and van Gieson, and Moore's modification of Weigert's elastic stain (either alone of counterstained with $1 \%$ aqueous pyronin). The sections were mounted in balsam on old washed photographie: half- and quarter-plates, and similar glassware was used for coverslips. When it was intended to examine the sections with a high power objective they were covered with many small thin coverslips.

\section{Dissection and Small Sections}

The lobes were examined by detailed dissection of the bronchial tree, using a fine grooved seeker and a razơ blade. Histological sections were taken from the areag most severely and least severely affected, and from the proximal ends of the involved bronchi. The same staining methods were used as with the large sections, with the addition, in some specimen's, of Perl's reaction for fre iron, and frozen sections stained for fat. 


\section{Bronchial Casts}

Neoprene latex was the most satisfactory of various injection materials used. The casts are firm but not brittle, and they have a flexibility that permits examination of those bronchi which in more rigid material would be inaccessible. Another advantage is that neoprene can be used to fill the alveoli as well as the bronchial tree without the cast fusing into an amorphous mass, for the filled alveoli can be removed in lobules by cutting through the bronchioles.

INJECTION TECHNIQUE.-The injection apparatus consisted of a neoprene stock bottle connected to a cannula by rubber tubing. The pressure of injection, provided by a gas cylinder, was measured with a sphygmomanometer and regulated with a hand control.

Specimens with adequate hilar bronchi and undamaged pleural surfaces were selected for injection. These were fixed for a month so that the tissues would be hardened to resist distension from the pressure of injections. In each specimen the larger bronchi were cleared of pus with fine Pasteur pipettes attached to a suction pump; a glass cannula was then tied into the hilar bronchus and filled with neoprene. After most of the air had been squeezed out of the specimen and cannula, and all air bubbles had been removed from the injection

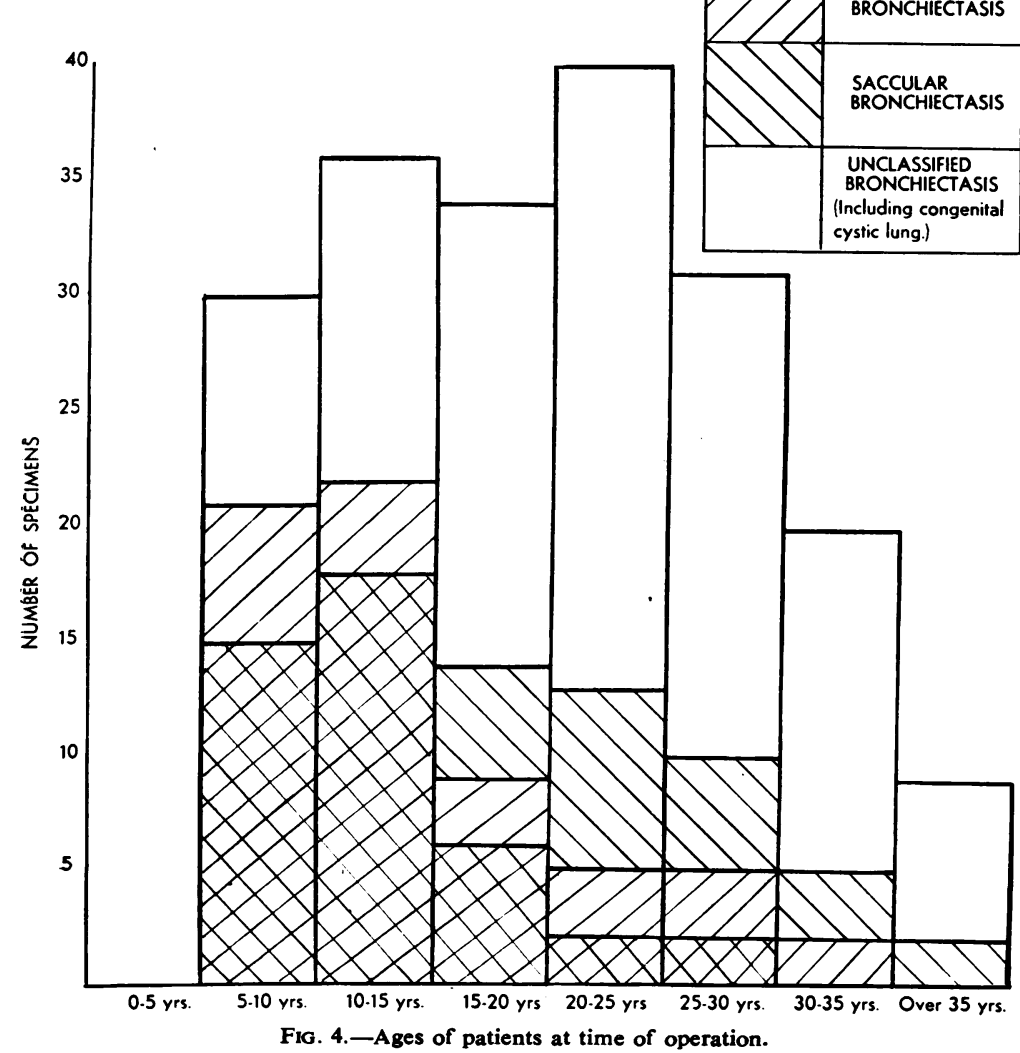

apparatus, the two were connected and injection was begun.

The injections were originally made at low pressures (10 mm. Hg.), and were stopped when any alveolar filling was seen, but this produced incomplete filling of some normal bronchi and bronchioles. Later injections were made at a pressure of $100 \mathrm{~mm}$. $\mathrm{Hg}$., which was maintained until complete alveolar filling of normal segments had been achieved. No distension of the air passages was produced by this high pressure, and the knowledge that normal parts of the bronchial tree had been completely filled was of value in assessing the extent of bronchial and bronchiolar obstruction in diseased areas.

After completing an injection the cannula tubing was clamped and divided, and the specimen with its sealed cannula was immersed in acidified formol saline for a few hours, then in changes of concentrated hydrochloric acid for a week. By this time all tissues had been destroyed and a solid cast remained, which was washed in running water. After noting the areas of alveolar filling, the alveoli were removed by cutting through the bronchioles (Figs. 1-3). As casts became brittle when exposed to air for a long time, they were stored in $5 \%$ formol saline.

\section{Some Macroscopic Features OF THE SPECIMENS' LOBAR DISTRIBUTION}

The 200 specimens came from 196 patients, each of four patients having had two separate lobectomies. The lobar distribution of the specimens can be seen in Table I, and the ages of the patients in Fig. 4.

Few specimens came from patients older than 40 years, or from those with extensive bilateral disease. The table indicates the sites most severely affected and most commonly involved, and is consistent with the findings of larger bronchographic surveys, such as those of Perry and King (1940) and Schmidt (1947).

The left lower lobe was removed over three times as often as the right lower lobe, and the lingula was resected in about half the cases where the left lower lobe was diseased. The right middle lobe 
TABLE I

Lobar Distribution OF SPECIMENS

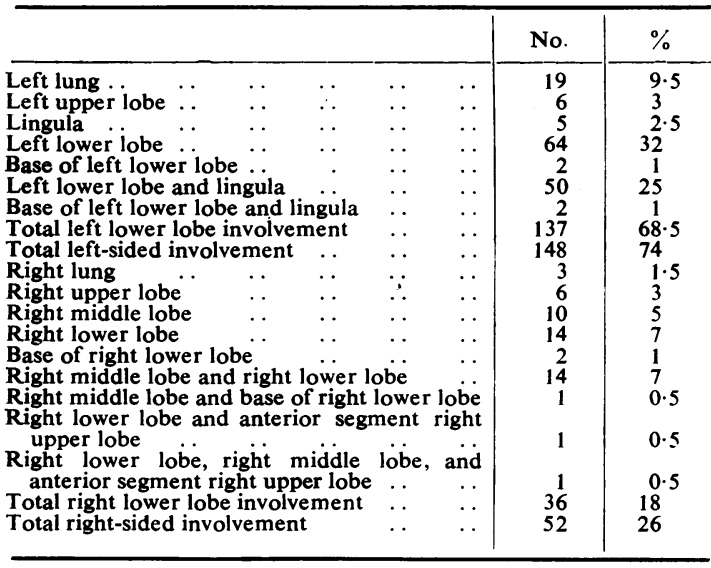

was involved slightly less often than the right lower lobe, and frequently with it.

\section{Segmental Distribution}

Bronchiectasis has often been described as a disease affecting the broncho-pulmonary segments, but such a description can be applied to almost any pulmonary disorder. The important fact is that bronchiectasis involves mainly the smaller bronchi, and both the bronchial and parenchymatous changes tend to remain localized. Very often only small parts of broncho-pulmonary segments are diseased, and the lesions are better described as focal. It is the treatment of bronchiectasis that is segmental, not the disease.

Churchill and Belsey (1939) have emphasized that bronchiectasis is often multilobar in distribution, but within a lobe the disease may be confined within one or more broncho-pulmonary segments. Overholt, Betts, and Woods (1947) have stated that the disease shows a predilection for certain segments. These and other opinions were based mainly upon clinical and bronchographic evidence, for there has been little mention of the subject in pathological accounts. In 1949, Moorè, Kobernick, and Wiglesworth studied the pathology of individual segments in seven operation specimens. They found little correlation between bronchographic and histological findings, for all the lower lobe apical bronchi appeared normal on bronchography and yet showed abnormal histology.

In discussing the segmental distribution of lesions in the present series there are two types of specimen to consider. The small, solid lobes and lungs, which on section showed severely collapsed alveoli with prominent and often dilated bronchi, nearly always showed a similar extent of disease in eaced segment. The rest of the specimens, which wers more bulky, at least partially aerated, and withou conspicuous collapse, contained many normal bronchi and the degree of involvement in affecteg segments was variable. The following remarks about segmental and intra-segmental distribution $\overrightarrow{0}$ lesions apply only to this second type, which represented nearly $90 \%$ of the specimens.

Among 114 complete left lower lobes were five in which the bronchiectasis was of similar extent in all segments, and all these specimens showedo severe alveolar collapse. The segmental distribution of lesions in the remaining 109 specimens is giverp in Table II. This shows that the apical segment $\mathrm{B}$ normal in three-quarters of the specimens, the anterior basal segment is normal in a quarter of the specimens, and the posterior basal segment nearly always diseased. This order of frequency of involvement is also usually the order of severit of the lesions within the segments in a lobe. Each lower lobe basal bronchus divides into an uppe्f and a lower branch; in most specimens the disease was more severe in the lower branches (Fig. 58 while in some instances only these branches were affected.

TABLE II

Segmental Site of Lesions in 109 Left Lower Lobes

\begin{tabular}{|c|c|c|c|c|c|c|c|}
\hline \multicolumn{6}{|c|}{ Segment } & Normal & Disease $\Phi$ \\
\hline $\begin{array}{l}\text { Apical } \\
\text { Anterior basal } \\
\text { Middle basal } \\
\text { Posterior basal }\end{array}$ & $\begin{array}{l}\cdots \\
\because \\
\cdots\end{array}$ & $\begin{array}{l}\cdots \\
\because \\
\cdots\end{array}$ & $\begin{array}{l}\cdots \\
\because \\
\cdots\end{array}$ & $\begin{array}{l}\because \\
\because \\
\because\end{array}$ & $\begin{array}{l}\because \\
\because \\
\cdots\end{array}$ & $\begin{array}{r}78 \\
30 \\
10 \\
4\end{array}$ & 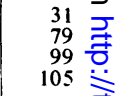 \\
\hline
\end{tabular}

Bronchiectasis in the upper lobe also shows predilection for certain bronchi (Figs. 6, 7, 8, and 9). The lingular bronchi are most frequent affected, particularly the lower branch; next if frequency come the anterior and posterior bronci (particularly their axillary branches), while the apical bronchus is rarely diseased (Fig. 10).

A similar kind of distribution is found in right. sided specimens.

\section{MoRphology of Bronchial CaSts}

Bronchiectasis is often classified from the shape of the dilatations, and although the terms cylindric and saccular are derived from early pathologiced descriptions, they are now used mainly in reporting bronchographic features.

From dissection of the bronchi and a study bronchial casts it is difficult usually to see an similarity between dilatations and the descriptike terminology, except in saccular bronchiectasis Casts prepared from severely bronchiectatic lobes 

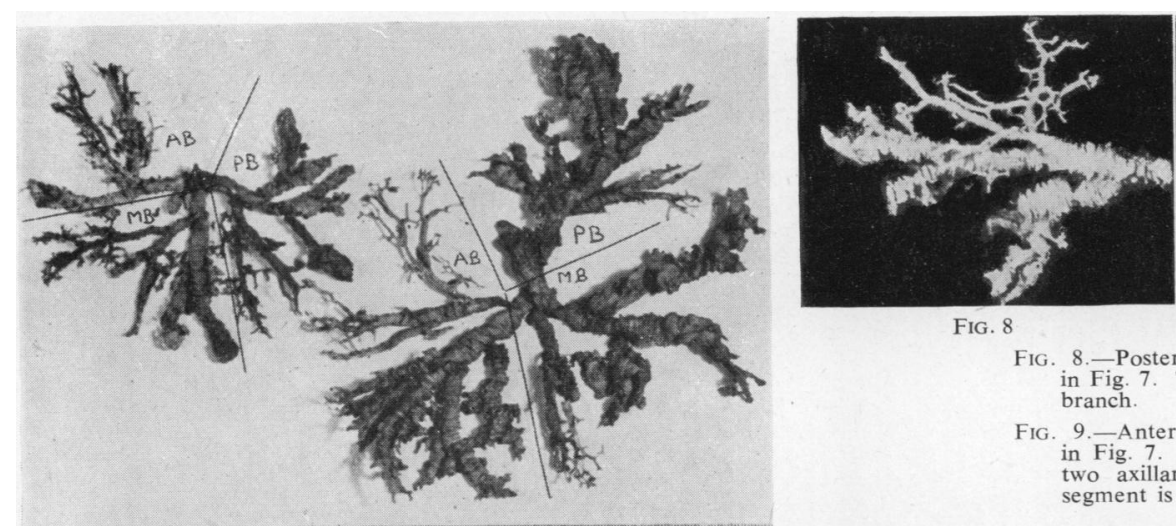

FIG. 8

FIG. 8.-Posterior bronchus from specimen in Fig. 7. This bronchus has one normal branch

FIG. 9.-Anterior bronchus from specimen in Fig. 7. There is gross disease of the two axillary branches, the rest of the segment is normal.

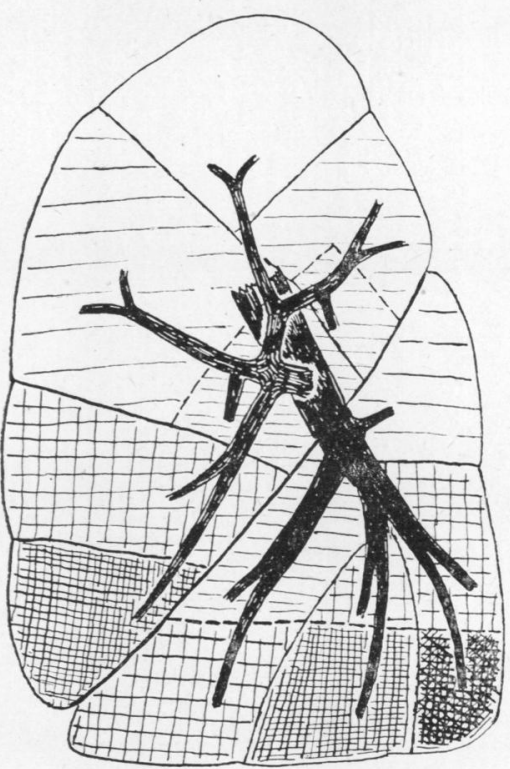

FIG. 10.-Distribution of left lung lesions (diagram after Brock).

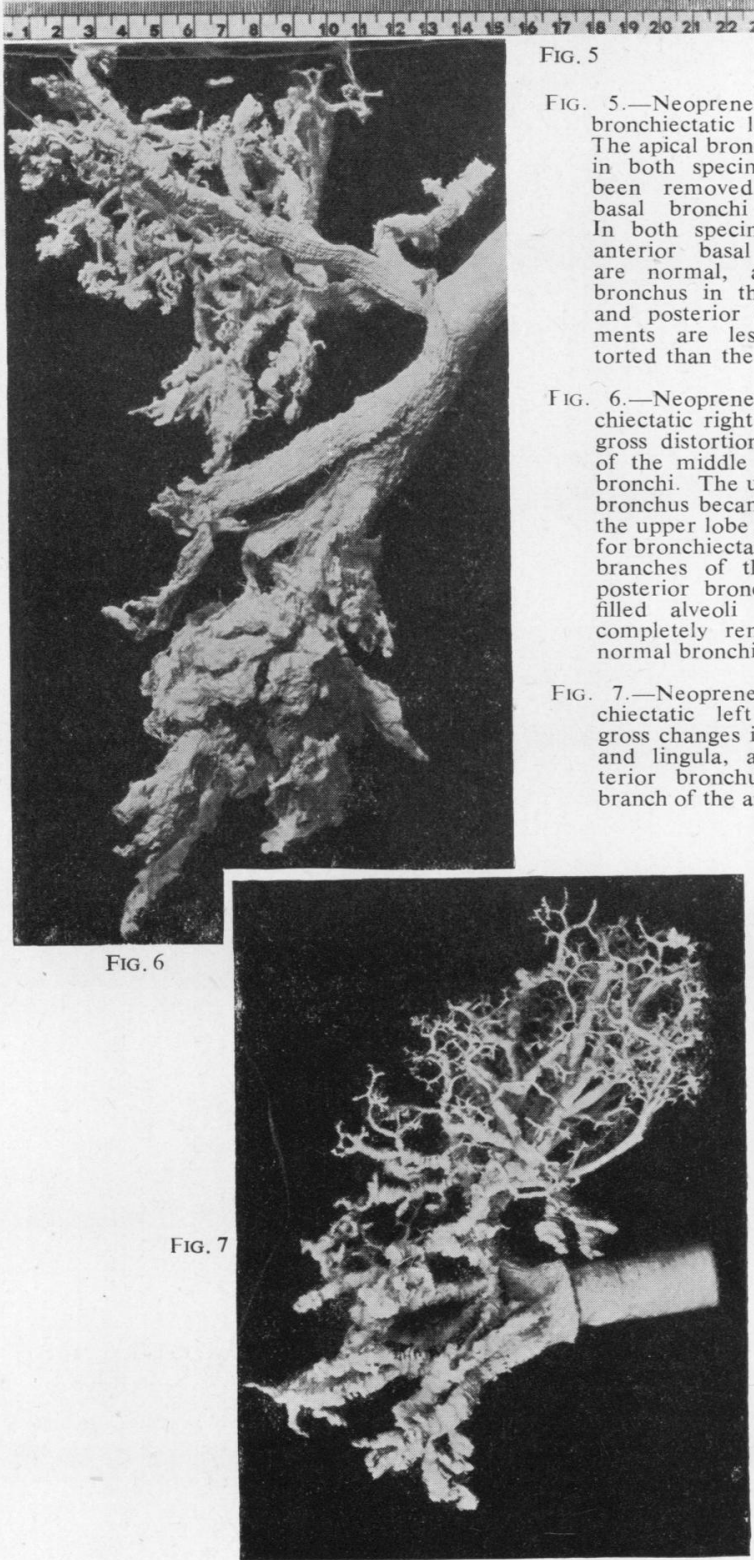

are extremely variable; often constrictions are as prominent as the dilatations, which are flattened and irregular in shape, e.g., the lower lobe in Fig. 6.

The mildest lesions produce thickening and transverse ridging for about $1 \mathrm{~cm}$. in the cast of a te minal bronchus, with no obstruction to the peripheral bronchioles and alveoli, which fill normally with neoprene. In the next stage these bronchial changes are accentuated, with partial obliteration of bronchiolar connexions. Severer lesions show more extensive involvement with greater irregularity of the dilatations, which are flattened and have no bronchiolar connexions (Figs. 11, 12, and 13). In many advanced cases there is dilatation of the first and second branchings of the segmental bronchi with complete obliteration of the distal bronchial tree.

Casts prepared from aerated lobes, where only a few segments are diseased, sometimes show 


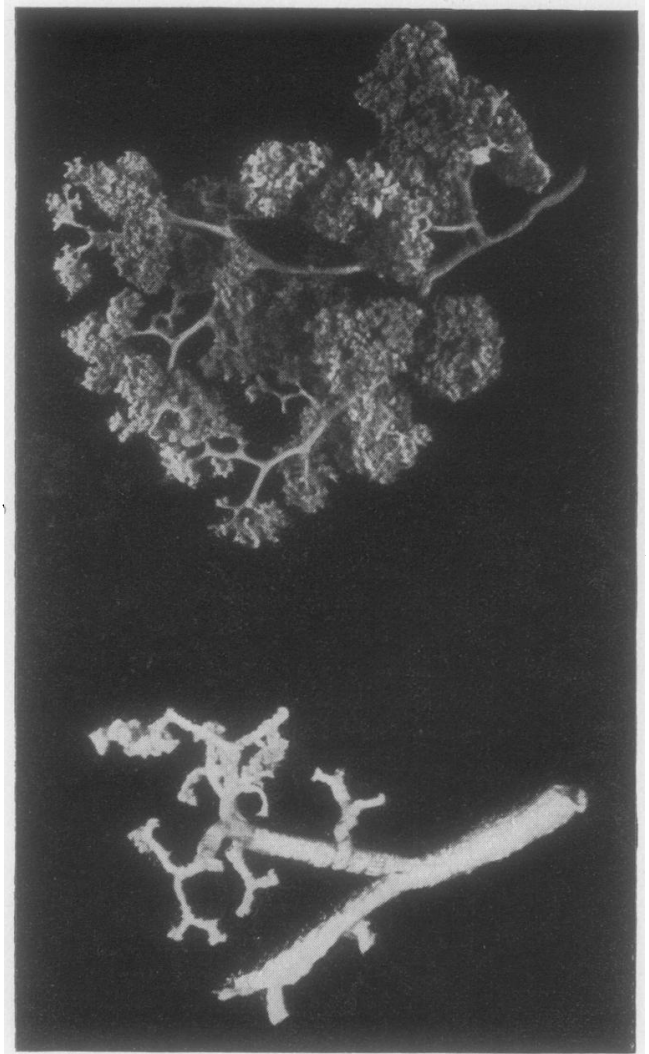

FIG. 11.-Neoprene cast of terminal part of normal bronchial tree. Upper cast is from a child of 3 years. Lower cast is from a man of 50 years (alveoli removed).

complete neoprene alveolar filling, even around the severely diseased bronchi. These bronchi are found embedded in alveoli but having no bronchiolar connexion with them, and there is a complete loss of lobular pattern in these air cells. It is probable that neoprene has reached these alveoli from existing collateral air passages through adjoining normal lung tissue.

\section{STRUCTURAL CHANGES IN BRONCHIECTASIS}

The variable severity of the lesions of bronchiectasis in different segments of a lobe was seen in the histological sections as well as in the casts. It is difficult to avoid regarding these different lesions as stages in the development of bronchiectasis, for it seems natural to regard gross structural changes as pointing to the original site of the disease and the mildly affected bronchi as the areas of latest extension. As clinical evidence is all against the view that bronchiectasis spreads from

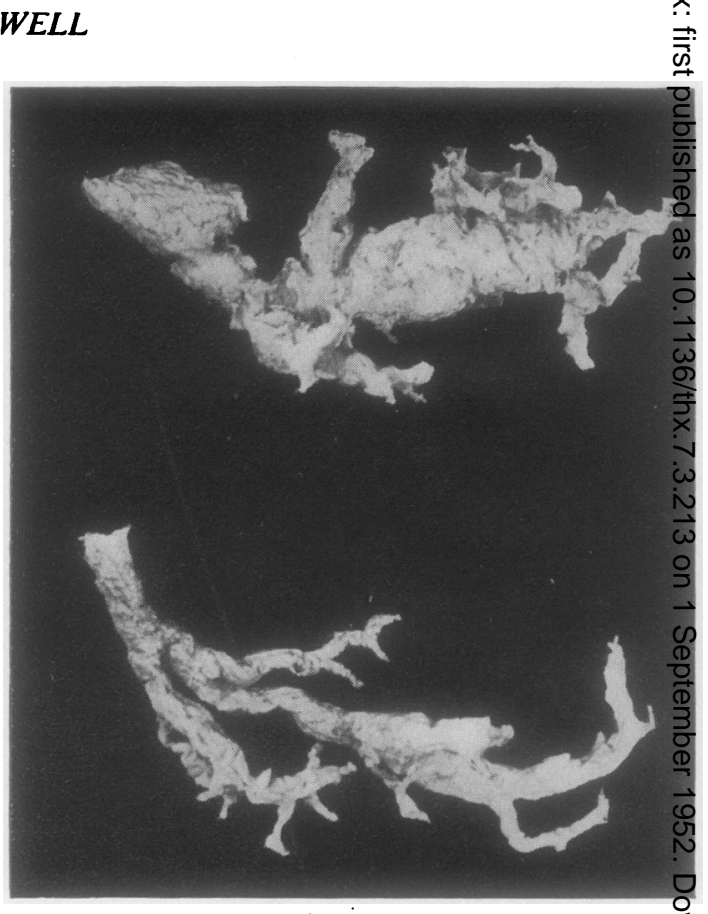

Fig. 12.-Neoprene casts of terminal bronchiectatic tree; branchioles are few and irregular and have no alveolar connexiems, and bronchi are thickened.

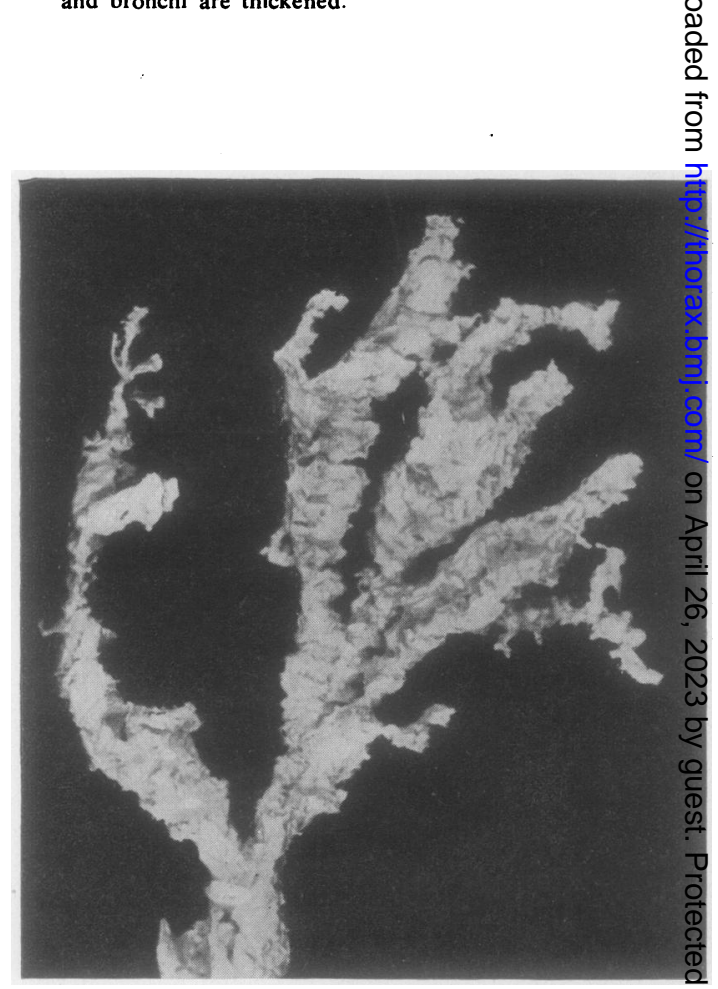

Fig. 13.-Neoprene cast of terminal bronchiectatic tree; browhi are flattened and irregular and have no bronchiolar connexions. 
one segment to another, a more likely explanation is that at the onset of the disease the bronchi are subjected to varying degrees of injury.

In areas of gross bronchiectasis it is difficult to distinguish the primary abnormality from its secondary effects, but in areas of milder bronchiectasis there are few secondary changes. The present study is based upon the examination of these milder lesions, which represent the basic pathology of the disease.

The 180 specimens that were examined microscopically included 22 examples of congenital or developmental bronchiectasis; these will not be discussed in the present account. Among the remaining 158 specimens there were 87 which belonged to one or other of three common types of acquired bronchiectasis. These have been called follicular, saccular, and atelectatic bronchiectasis, and their pathology, pathogenesis, and clinical features will now be discussed.

\section{FOLLICULAR BRONCHIECTASIS}

The term "follicular" has been chosen because the most prominent microscopic feature is an excessive formation of lymphoid tissue, occurring as follicles and nodes, which are situated both in the walls of diseased bronchi and bronchioles, and among the surrounding alveoli.

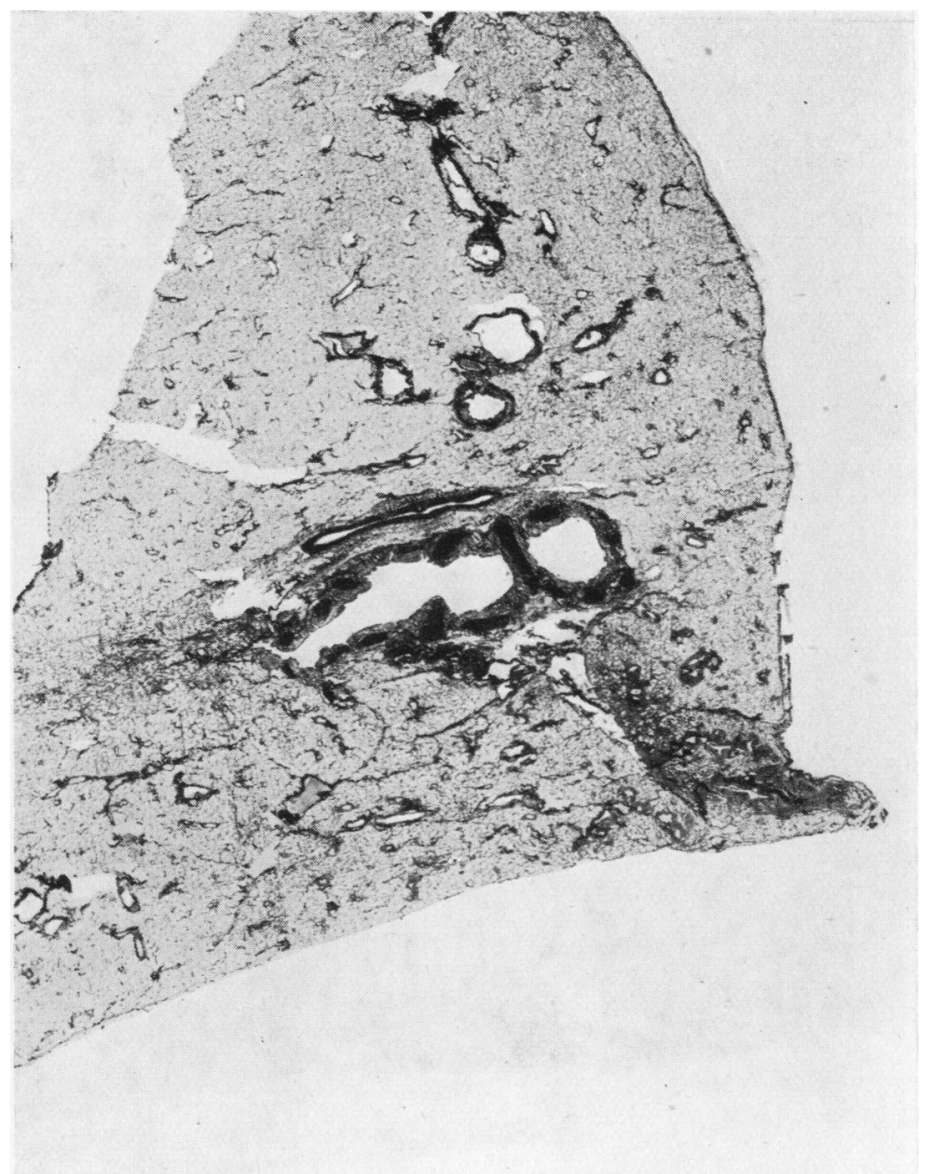

FIG. 14.-Mild follicular bronchiectasis of left lower lobe (Case 464). Haematoxylin and eosin.

These lesions are usually associated with great enlargement of hilar lymph nodes.

The three examples to be described are mild, moderate, and severe cases of follicular bronchiectasis; in the second and third cases the account will be limited to the features not seen in previous specimens.

Reasons will be given for regarding these tissue changes as specific, and the pathology, clinical features, pathogenesis, and aetiology of this condition will be discussed.

\section{Mild Follicular Bronchiectasis}

CASE 464.-A 6-year-old girl had suffered from a productive cough since the age of 18 months, with occasional acute pyrexial exacerbations. She was dyspnoeic on exertion, showed finger-clubbing, and had purulent sputum. At bronchoscopy pus was seen exuding from the left lower lobe bronchus, and broncho- grams showed bronchiectasis of the left lower lobe, mainly in the posterior basal segment. This lobe was removed.

Macroscopic Appearance of Specimen.-The lobe is bulky, aerated, moderately pigmented, and covered by shiny pleural membrane, except over the base of the posterior basal segment, where the membrane is thickened. Enlarged lymph nodes are adherent to the lobar bronchus at the hilum.

Sections made through the lobe show only slight abnormality, and the lesions seen in Fig. 14 are as extensive as in any area. The disease is limited to the lower part of the posterior basal segment, and, although the segmental bronchus appears normal, some of its branches are dilated and thickened, and contain pus.

The alveoli around these branches have a grey-white, translucent granularity indicating interstitial pneumonia, and there are some small brown sunken areas of collapse under the pleural membrane. 


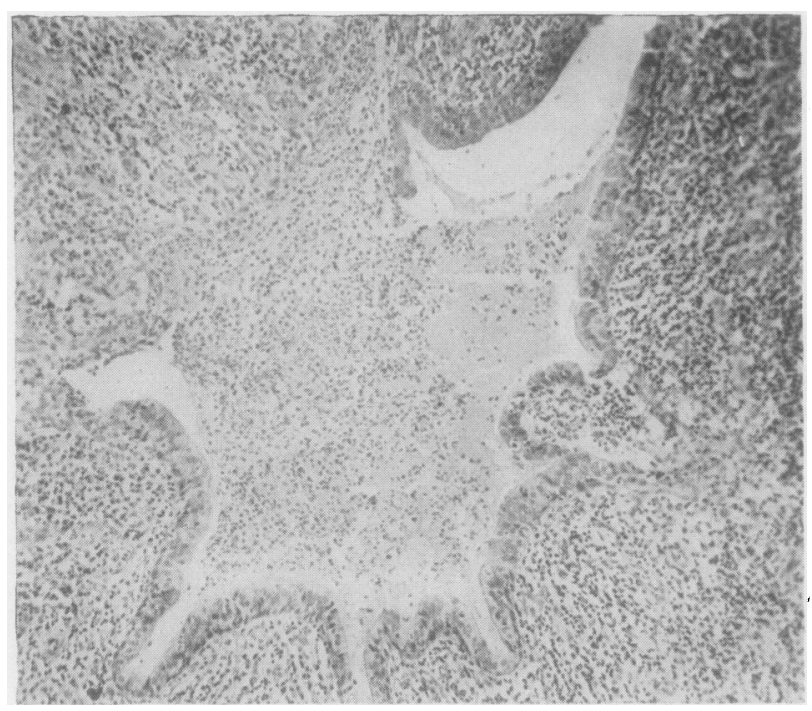

Fig. 15.-Ulcerated wall of bronchiole. Haematoxylin and eosin $\times 110$.

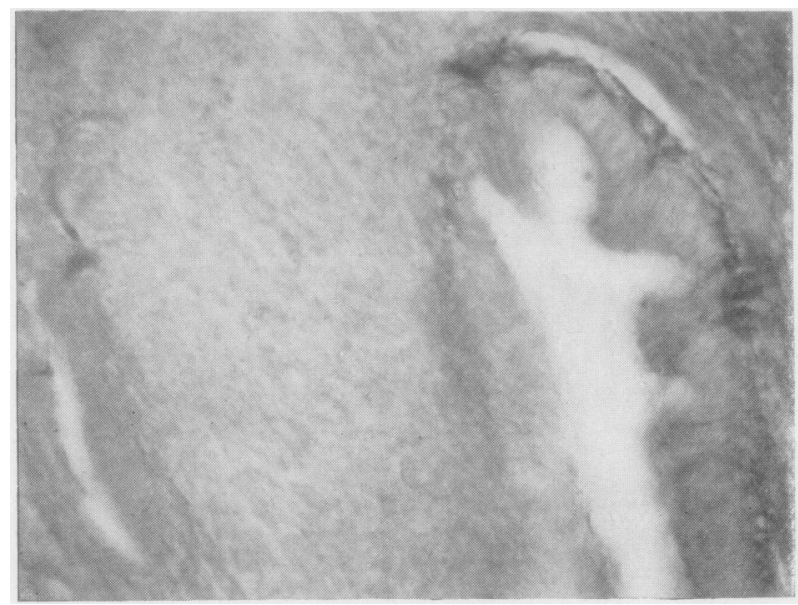

FIG. 16.-Interruption of bronchiolar elastic tissue near lymph follicle. Elastic stain and pyronin $\times 256$.

Microscopic Features.-The only area to be described is the posterior basal segment; no other segments show any abnormalities.

The only notable features of the posterior basal bronchus are an excessive vascularity of sub-epithelial tissues, and lymphocytic aggregations around the mouths of mucous-gland ducts. Elastic tissue, muscle, and cartilage appear normal.

The bronchi of the posterior basal bronchus are filled with pus, and lined by ciliated columnar epithelium, which has no surface ulceration or squamous metaplasia. The bronchial walls are about three times their normal thickness, because of distension with oedema fluid, dilatation of sub-epithelial capillaries, aggregations of lymphoid cells, and infiltration with chronic inflammatory cells which are mainly plasma cells and lymphocytes.
Lymphoid aggregations are indistinguishatde from the follicles and nodes of lymph glands, and they are situated in sub-epithelial tissues, and $\overline{\overline{\mathrm{m}}}$ deeper parts of the bronchial walls. In the formor site they cause distortion and partial occlusion of the bronchial lumina, while the intra-mural follictos produce stenosis of the bronchial branchings.

Bronchial supporting tissues are extensively damaged, particularly near the lymph folliclese, where there is no elastic tissue, only a few frag ments of muscle survive, and even the cartilage $\frac{3}{x}$ partly destroyed. Peribronchial fibrous septa are thickened and contain dilated lymphatics. $\dot{\omega}$

The inflammatory reaction seen in the brondhi is also present in the bronchioles, where, because of their thinner walls and narrower calibre, the effects are more severe. Though some are dilated. most of them are compressed and either parths or completely occluded by the inflammatofy swelling of their walls.

Cuboidal or columnar cells make up the epithilium in which surface erosions occur. Small acựe ulcers show pus streaming into the lumina from uncovered areas of vascular granulation tissue bronchiolar walls (Fig. 15). Where healing has begun the granulation tissue is much less inflamed and is covered by layers of flattened cells whige sprout from healthy, adjoining epithelium. Later stages show the replacement of granulation tiss by small areas of fibrosis, and conversion of the layers of cells into a cuboidal epithelium.

Some bronchioles have escaped both the generalized inflammatory thickening and the surface erosions, and contain normal musete layers with some lymph follicles and nods. Elastic stains show, however, that there is des truction of elastic tissue where it lies close to the follicles, even when there is no diffuse
flammatory reaction.

While mildly affected bronchioles may embedded in normal aerated alveoli, most of those which are diseased are surrounded by a rim @f chronic interstitial pneumonia, the width of whieh is proportional to the severity of the bronchioger lesions.

In such zones of interstitial pneumonia the alveoli are separated, small, globular, and lined by cuboidầ cells, while the interstitial tissues are oedematous affl contain plasma cells and lymphoid tissue. Usually alveoli lying outside areas of pneumonia are norm出, but in some lobules they are collapsed.

Branches of the pulmonary artery accompanying diseased bronchioles are surrounded by dense fibres tissue. The inter-lobular fibrous septa are thickenef.

\section{Moderate Follicular Bronchiectasis}

CASE 758.-This 11-year-old girl had suffered fromp cough since acquiring measles when 18 months offit, and her symptoms increased after whooping cough $\sigma_{6}$ t the age of 4 years. On examination she had a productpe cough and finger clubbing, and bronchograms showed 
cylindrical bronchiectasis of the left lower lobe and lingula, with minimal changes in the right middle lobe. Left lower lobectomy with removal of the lingula was performed.

Macroscopic Appearance of Specimen.-The lingula is small and firm, and has a shiny, thin pleural covering. Sections show the bronchi to be dilated, thickened, filled with pus, and surrounded by interstitial pneumonia. The microscopic appearance is similar to that of the posterior basal segment (q.v.).

The lower lobe appears well aerated, though the basal segments contain some firm areas. The pleural membrane is normal: there are enlarged hilar lymph glands.

Sections of the lobe (Fig. 17) show more extensive disease than in Case 464. There is marked thickening and dilatation of all branches of the posterior basal bronchus, and extensive pneumonia in this segment. Changes in the middle and anterior basal segments are of lesser severity, and are comparable with those seen

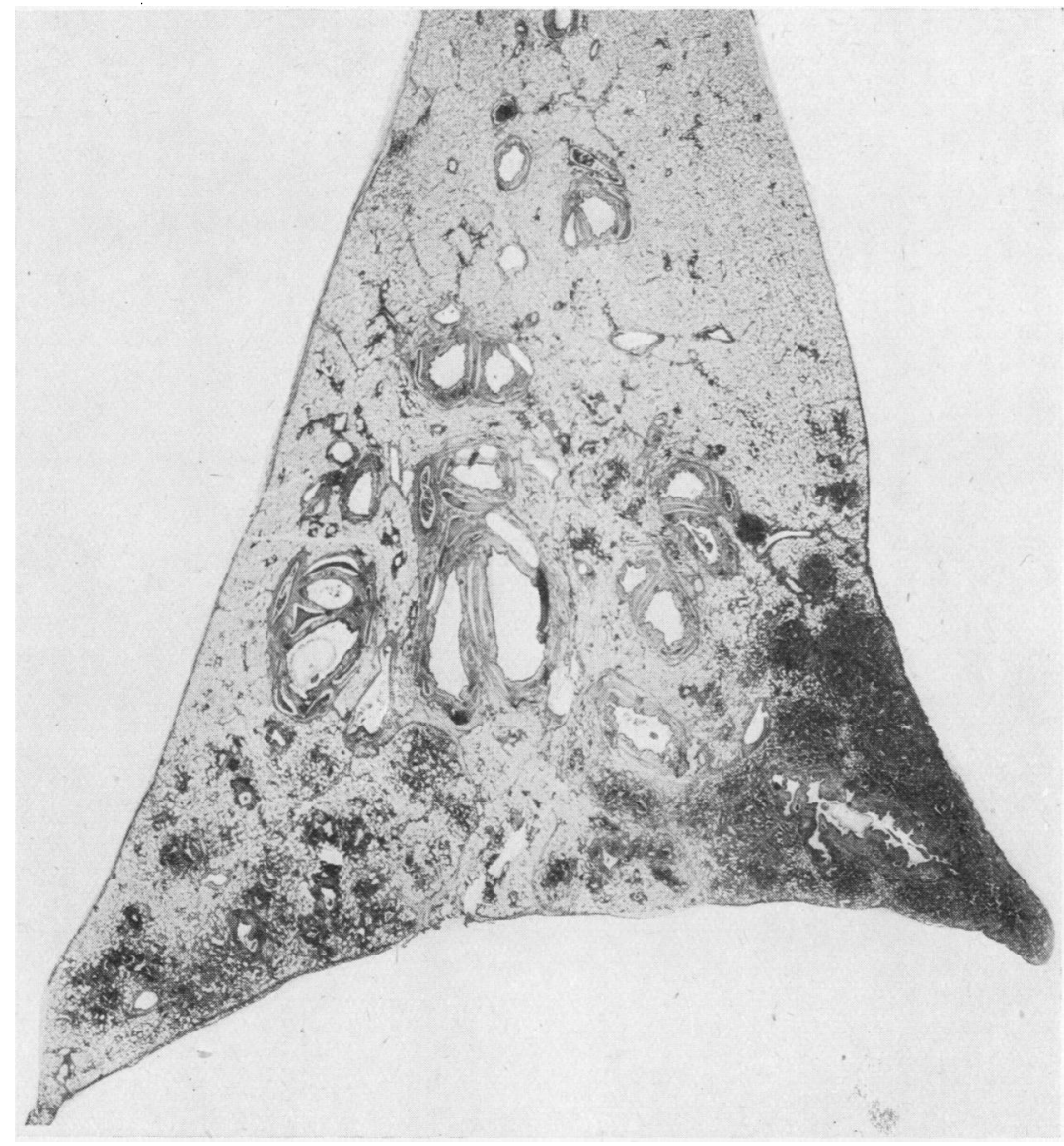

FIG. 17.-Moderate follicular bronchiectasis of left lower lobe (Case 758). Iron haematoxylin and van Gieson.

All bronchioles in the segment are diseased, most of them being partly occluded, while some appear almost obliterated. Epithelial changes follow those in the previous specimen, but the inflammatory reaction is more extensive, lymph follicles are more numerous, and there is almost total loss of muscle and elastic tissue.

In some fields the zones of interstitial pneumonia are so wide that they form a confluent mass. As there is little thickening of interlobular septa, the original lobular pattern is obliterated. No alveolar collapse is present.

\section{Severe Follicular Bronchiectasis}

CASE 497.-A 9-year-old girl, who had suffered from a productive cough since measles in early childhood, was admitted with an acute exacerbation of symptoms. She was dyspnoeic on slight exertion, showed finger clubbing, and bronchograms revealed bronchiectasis of the left lower lobe and lingula. Left lower lobectomy with excision of the lingula was performed.

Microscopic Appearance of Specimen.-The lingula is small and firm, and shows gross bronchiectasis with 


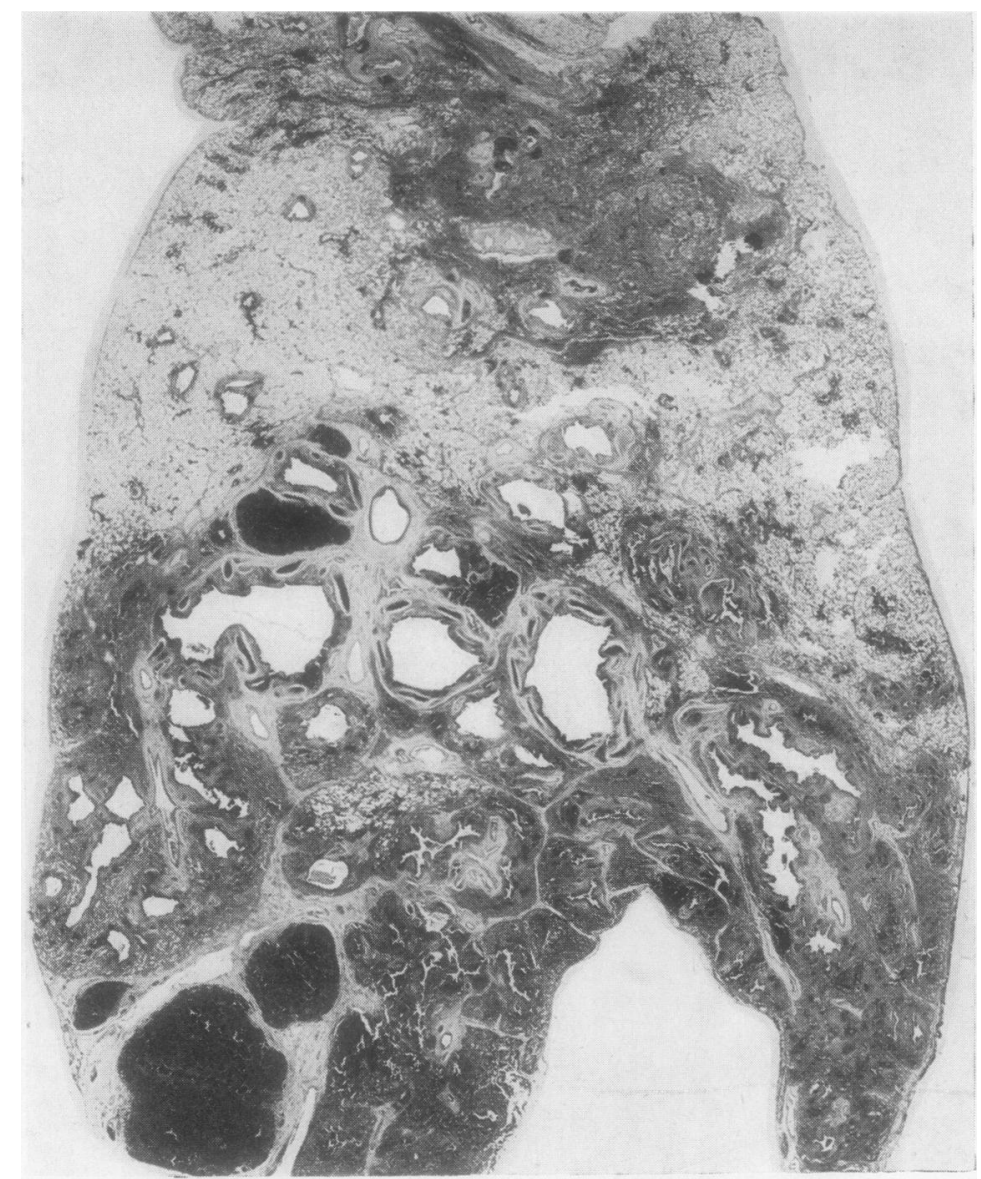

FIG. 18.-Severe follicular bronchiectasis of right lower lobe $2 \mathrm{~cm}$. from hilum (Case 497). Haematoxylin and eosin.

interstitial pneumonia and collapse. The microscopic features do not differ from those at the base of the lower lobe.

The lower lobe is quite bulky and firm, and has enlarged hilar lymph glands. The pleural membrane is thickened over the base of the lobe, but normal at the apex, which is partly aerated.

On section (Figs. 18 and 19) there is mild bronchiectasis with some pneumonia in the partially aerated apical segment, while the basal segments all show gross bronchiectasis with pneumonia, collapse, and some fibrosis. It is mainly in the segmental bronchi and their first and second branchings that dilatation is seen: more peripheral bronchi look like narrow clefts in solid tissue. The disease is most severe in the lower parts of the basal segments.

Microscopic Features.-Though the gross appearance is far removed from that of the previous two specimens there are no qualitative differences in the histology. Changes in the apical segment are similar to those described in mild lesions of the previous cases. The lesions in each basal segment gre of equal severity.

There is some dilatation but liê̄e thickening of the basal segmentral bronchi, and while epithelial liniggs are normal, there is diffuse inflaxnmatory infiltration of sub-epithe就 tissues with some lymph follicle formation. Elastic tissue is extersively destroyed, but the loss of muscle is only slight and cartila are normal. Mucous glands aje small and scanty; they lie closectoo the bronchial epithelium and haye very short ducts.

The proximal branches are dilafed and distorted, but more peripheral ones are flattened. Their histology is similar to that described an corresponding bronchi of क्रु⿰亻 previous case.

In some areas the lesions similar to those in severely affected parts of previous specimens (Fig. 26).

Sometimes, particularly near the diaphragmatic surface of the lobe, it is impossible to define the ouker walls of air passages, or to fesstinguish bronchi from bronchiofts. Granulation tissue in the broncligal and bronchiolar walls merges whth the confluent interstitial pneumo forming a granulomatous masss, which contains epithelium-liạd clefts and patches of collapse. There are so many lymph follicfes throughout this granulomatous tis that the pulmonary lobules resemple lymph glands. No bronchial süpporting tissues survive; thickened interlobular seja, however, help to identify the original outline of lobutes. The close relationship of thickened branches of the pulmonary artery to the epithelium-lined clefts suggests that the latter were originally bronchi and bronchiofes, and unlikely to be re-epithelialized pulmonary excapations.

\section{THE PATHOLOGY OF FOLLICULAR BRONCHIECTASIS}

These examples demonstrate that lesions nfiay range from a relatively minor and inconspicurus focus in one bronchopulmonary segment of otherwise normal lobe, to formation of a more less solid lobe which bears little resemblance to the normal.

In this investigation over a third of the specims showed features similar to the illustrated examp?es, with their typical microscopic lesions, the mest constant and characteristic of which were the forma- 
tion of lymph follicles and interstitial pneumonia.

\section{LYMPH FolliCle Formation}

Severely diseased bronchi and bronchioles contain many lymph follicles and nodes within their thickened walls, but, although this lymphoid tissue is extremely prominent, it forms only part of an extensive mural inflammation. At this stage of the disease there is widespread destruction of bronchial elastic tissue, muscle, cartilage, and mucous glands.

From the examination of many specimens it appears that elastic tissue is the first of the supporting tissues to be destroyed in bronchiectasis, muscle is the next to suffer, and cartilage survives the longest. Mucous glands are also destroyed, surviving for about as long as cartilage. It is thought that once any of these specialized tissues has been destroyed it cannot regenerate.

In areas of very mild bronchiectasis the only abnormalities in the bronchial tree are sub-epithelial accumulations of lymph follicles and nodes, and some oedema. Diffuse inflammation is not present and both muscle and cartilage appear normal; special stains, however, show that there is destruction of elastic tissue near the lymph follicles (Fig. 16). It is considered that this loss of elastic tissue is a fundamental lesion in follicular bronchiectasis, for once part of the bronchial tree has been damaged in this manner it is permanently weakened and incapable of overcoming secondary infections.

Apart from their destructive influence on elastic tissue, the lymph follicles, merely because of their size, distort the affected bronchial tree. Sub-epithelial follicles project into the lumina causing partial obstruction, while intramural follicles enlarge bronchial walls, compressing the openings of peripheral branches of the bronchial tree which enter the diseased bronchi. Similar but more severe effects are seen in the bronchioles, where complete occlusion is often produced.

Lymph follicles and nodes are present in normal lungs; Miller (1947) and Engel (1947) agree that lymphoid tissue occurs at points of bifurcation of bronchi and

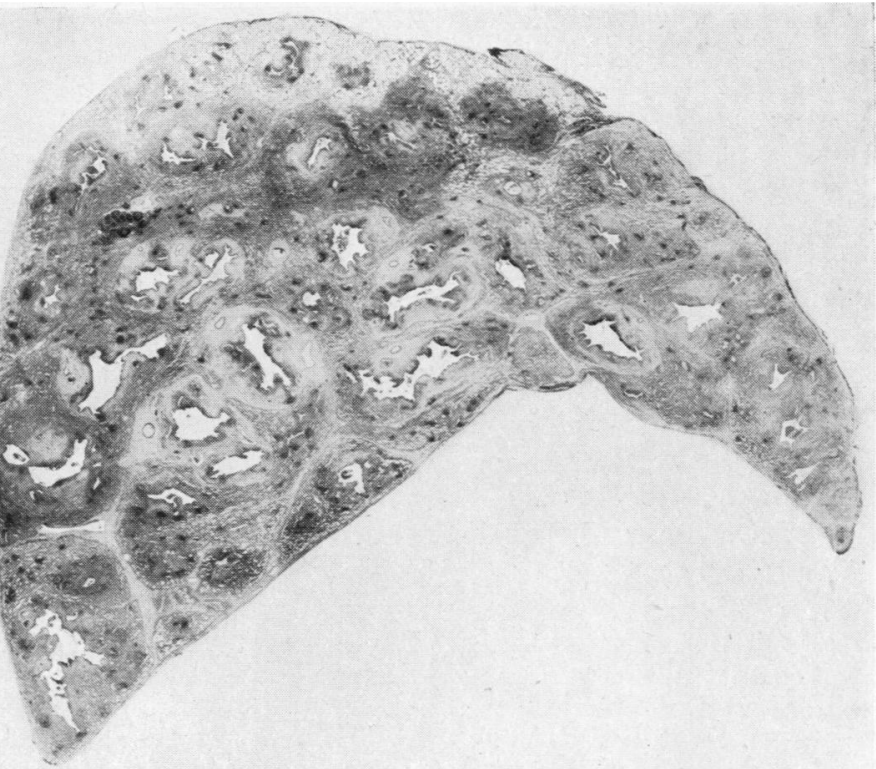

Fig. 19.-Same lobe as in Fig. 18, $5 \mathrm{~cm}$. from hilum. Haematoxylin and eosin.

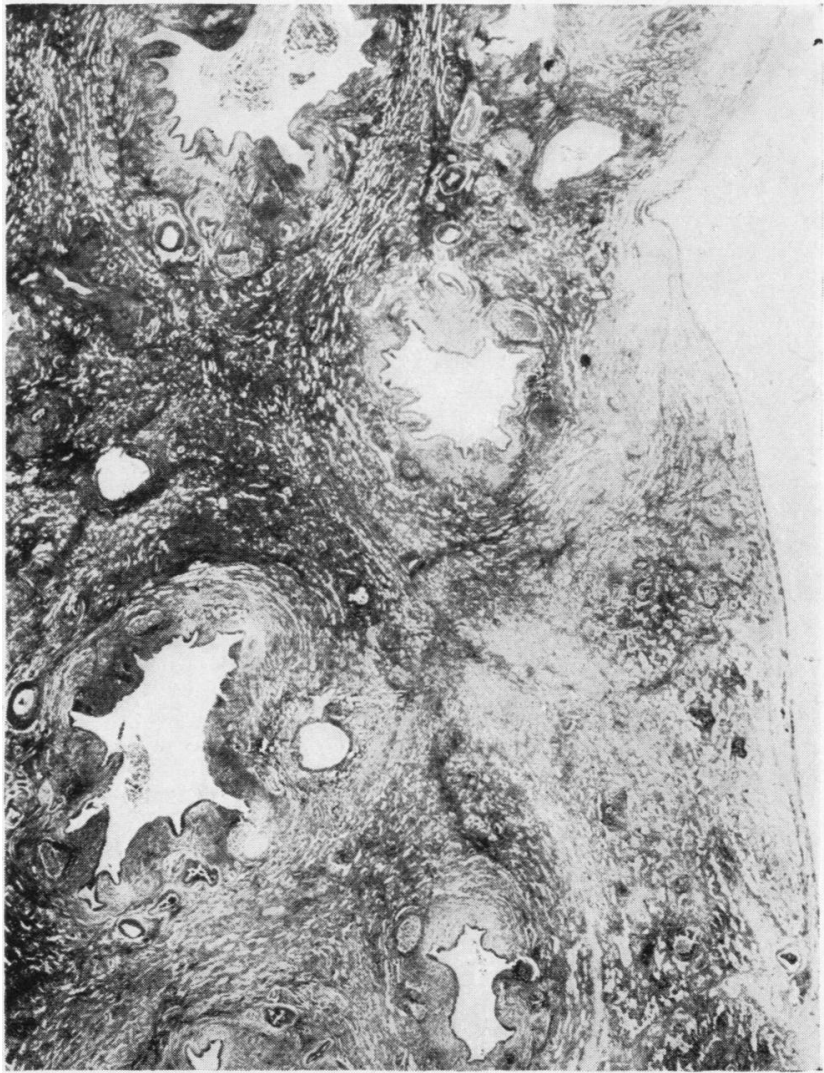

FIG. 20.-Follicular bronchiectasis. Haematoxylin and eosin $\times 10$. 
bronchioles, and between bronchioles and branches of pulmonary arteries which accompany them. A study of normal lung segments has confirmed this, and has shown that this lymphoid tissue is outside the bronchial tree, where no alteration of elastic tissue is to be seen.

Abnormal lymphoid accumulations in the lung are sometimes seen in other forms of bronchiectasis, around chronic lung abscesses, and in tuberculosis. In these conditions the number of follicles is much smaller and they are mostly situated outside the bronchial tree, but local destructive changes do occur near the occasional ones found in the bronchi.

Many authors (Robinson, 1933; Ogilvie, 1941; Allison, Gordon, and Zinnemann, 1943) have mentioned the presence of these bronchial lymph follicles in bronchiectasis, but their significance has not been studied, and only Engel (1947) has noted the associated loss of elastic tissue. He has called this condition " nodal bronchitis and bronchiolitis" and has described thickened collapsed bronchi and bronchioles where the walls contained lymph nodules but no diffuse cellular infiltration. A marked loss of elastic tissue occurred near the nodules, and this was noted too often for it to be fortuitous. Engel commented that he was unable to decide whether this lesion was caused by virus, an unusual infection, or some other influence?

\section{INTERSTITIAL PNEUMONIA}

Interstitial pneumonia is to be seen in othex pulmonary conditions, but it is a constant feature of follicular bronchiectasis. The pneumonia found in the parenchyma around affected bronk chioles, and its extent is dependent upon the severity of the bronchiectasis.

In normal lung tissue the respiratory part of the organ appears in section as a lace-work of large spaces separated from one another by thin-walled septa (Maximow and Bloom, 1942). These finfe inter-alveolar septa contain capillaries, elaste fibres, and a fine reticulum of connective tissue and in normal parenchyma such interstitial tissue are inconspicuous.

In interstitial pneumonia, however, the peri $\overrightarrow{6}$ bronchiolar and inter-alveolar connective tissues are oedematous, and contain infiltrations of plasm cells, mononuclears, and lymphocytes, together with occasional lymph follicles, dilated capillaries and lymphatics. The vas increase in bulk of interstitial tissues $\mathbb{R}$ associated with a reduction in volum of the alveoli, and an alteration of the lining cells.

Cells lining normal alveoli are inconspicuous, but in interstitia隹 pneumonia the alveoli are lined b? an epithelium of small cuboidal cells. The origin of this epithelium is obscure some think it is a down-growth of bronchiolar epithelium, others regare it as a metaplasia of cells normally found lining alveoli, while Watts and McDonald (1948) think that both these processes occur.

In mild bronchiolar lesions only thos alveoli actually in contact with the bronchiolar walls appear to have unde? gone this epithelialization; in fact? in many instances only parts of these alveoli are affected. As these altereg alveoli are often only found in the periphery of pulmonary lobules, $\overrightarrow{i t}$ seems unlikely that the lining cells are a bronchiolar down-growth, and moo probable that local metaplasia hos occurred as a result of interstitial in flammation.
Fig. 21.-Development of bronchiolar lesions and secondary lobular collapse in follicular bronchiectasis. 


\section{Clinical Features of Follicular Bronchiectasis}

The ages of all the patients were obtained from the register, but only two-thirds of the case-records were available for analysis.

The age distribution of all the cases of follicular bronchiectasis is shown in Fig. 4. Other details were obtained from the 28 case-records, and are as follows :

\begin{tabular}{|c|c|c|c|c|c|c|}
\hline \multicolumn{7}{|c|}{ AGE AT OPERATION } \\
\hline Under 6 yrs. & $\ldots$ & $\cdots$ & $\cdots$ & . & \multirow{2}{*}{\multicolumn{2}{|c|}{$\begin{array}{l}1 \text { patient } \\
9 \text { patients }\end{array}$}} \\
\hline $6-8$ yrs. $\ldots$ & . & . & .. & . & & \\
\hline $9-11$ yrs. .. & $\cdots$ & . & .. & . & 8 & , \\
\hline $12-14$ yrs. . & $\ldots$ & $\ldots$ & $\ldots$ & $\ldots$ & 4 & ,, \\
\hline $15-17$ yrs. . & $\ldots$ & $\ldots$ & . & $\cdots$ & 4 & ,, \\
\hline $18-20$ yrs. . & $\cdots$ & $\cdots$ & . & . & 2 &, \\
\hline Over 20 yrs. & . & $\cdots$ & . & . & 0 & , \\
\hline \multicolumn{7}{|c|}{ Age AT ONSET OF SYMPTOMS } \\
\hline Under 3 yrs. & .. & . & . & . & \multirow{6}{*}{\multicolumn{2}{|c|}{$\begin{array}{c}15 \mathrm{p} \\
7 \\
2 \\
2 \\
2 \\
0\end{array}$}} \\
\hline $3-6$ yrs. .. & $\ldots$ & . & . & . & & \\
\hline $7-9$ yrs. $\ldots$ & . & . & . & . & & \\
\hline $10-13$ yrs. . & . & . & $\cdots$ & . & & \\
\hline 14-18 yrs. . & $\cdots$ & . & . & $\cdots$ & & \\
\hline Over 18 yrs. & $\cdots$ & $\cdots$ & $\cdots$ & $\cdots$ & & \\
\hline \multicolumn{4}{|c|}{ Pre-operathe Euration } & \multicolumn{3}{|c|}{ SYMPTOMS } \\
\hline Under 1 yr. & . & . & . & . & \multicolumn{2}{|c|}{0 patients } \\
\hline $1-3$ yrs. $\ldots$ & $\cdots$ & $\cdots$ & $\cdots$ & $\cdots$ & 7 & , \\
\hline 4-5 yrs. & $\cdots$ & $\cdots$ & $\cdots$ & $\cdots$ & 7 & , \\
\hline $\begin{array}{r}6-10 \text { yrs. } . \\
11-15 \text { yrs. }\end{array}$ & $\ddot{x}$ & 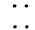 & $\ddot{*}$ & $\cdots$ & 10 & $\because$ \\
\hline Over 15 yrs. & $\ddot{*}$ & 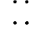 & $\ddot{m}$ & $\because$ & 2 & ", \\
\hline
\end{tabular}

Nature of Illness at ONSET OF Symptoms

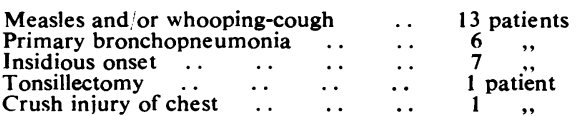

Finger Clubbing

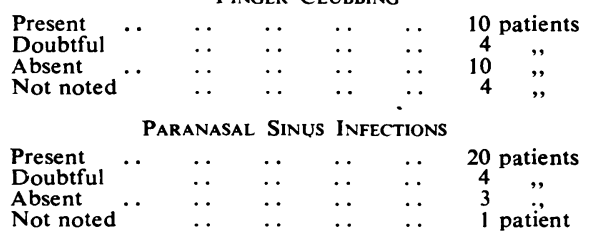

The severity and extent of the disease appeared to be unrelated to the nature or severity of the initial illness, or to the duration of the symptoms.

Patients with finger clubbing did not have the more extensive or severe pulmonary lesions; there was also no correlation between finger clubbing and duration of symptoms.

There was obvious correlation between the nature of the patients' sputa and the degree of inflammation in the bronchi.

\section{Pathogenesis of Follicular Bronchiectasis}

The main lesions occur in smaller bronchi, bronchioles, and in alveoli, while minor secondary changes take place in the larger bronchi. The more severe the involvement of the lobe, the more proximally does each of these processes extend, with obliteration of the distal bronchial tree. Secondary changes in the larger bronchi include the destruction of supporting tissues around the mucous gland ducts, which then enlarge and form part of the bronchial wall.

Small bronchi and bronchioles are affected similarly; only the bronchiolar changes will be described as these are more closely associated with the parenchymal disease. By studying lesions of different severity it is possible to visualize the evolution of the advanced condition (Fig. 21).

The early changes consist of thickening of bronchiolar walls due to oedema and lymph follicle formation, with destruction of elastic tissue near the follicles. These bronchioles are usually rather flattened, and are surrounded by narrow rims of interstitial inflammation.

More advanced lesions show a greater number of follicles and a diffuse mural bronchiolitis, with destruction of all elastic tissue and most of the muscle. The bronchiolar lumina are reduced and often appear stellate on cross-section. Interstitial inflammation involves wider areas of the parenchyma, and there is fibrosis around branches of the pulmonary arteries. Often the interlobular septa and pleural membrane are thickened. 5

Alveolar collapse has been seen only in specimens where there was thickening of interlobular septa and pleural membrane. Microscopically this collapse is of the type produced by compression, and its distribution is lobular.

The cause of the alveolar collapse can be found in the lobules (Fig. 21). Thickened interlobular septa and pleural membrane keep the outline of a lobule rigid, but as the centre contains an expanding granulomatous mass (which has arisen from the bronchiole and peribronchiolar tissues) pressure within the lobule becomes raised. This tension produces both flattening of the weakened bronchiolar walls, which reduces the lumen to a narrow cleft, and compression collapse of the alveoli outside the area of pneumonia.

\section{The Aetiology of Follicular Bronchiectasis}

The important clinical facts are that the condition usually begins in early childhood and is a sequel to whooping-cough, measles, or primary bronchopneumonia. This bronchiectasis may also have an insidious onset.

The essential lesions are destructive mural bronchitis, bronchiolitis, and interstitial inflammation, and the pathology appears very closely related to the acute interstitial pneumonias which were reported by MacCallum (1940) in fatal cases of measles and influenza and whooping-cough. MacCallum described the lesions found in service personnel, but Engel (1947) has reported a similar 


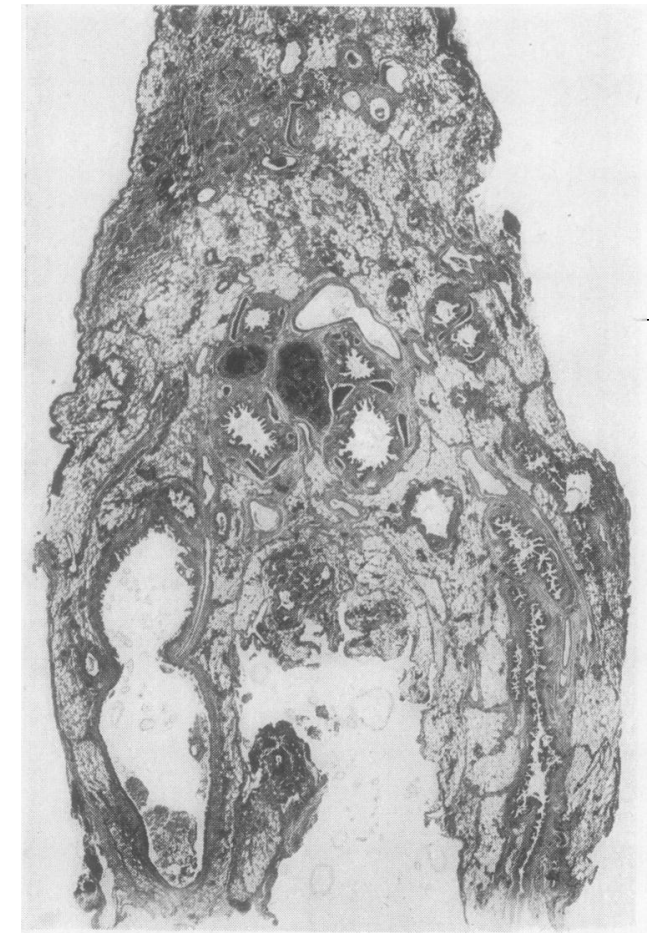

FIG. 22.-Saccular bronchiectasis of right lower lobe (Case 395) $2.5 \mathrm{~cm}$. from hi.um. Haematoxylin and eosin $\times 1.5$.

multifocal condition in children, under the name of destructive mural bronchiolitis. MacCallum says that this condition always follows a virus infection and haemophilic organisms can usually be grown from the lungs, and Engel has suggested a viral origin for his " nodal bronchiolitis."

Follicular bronchiectasis is very like rodent bronchiectasis (Cruikshank, 1948), which has keen shown by Nelson (1946) to be of viral origin.

Follicular bronchiectasis is probably the sequel of acute viral infection of the lungs contracted in early childhood. Usually this infection occurs with whooping-cough or measles, or, when influenzal it is described as primary bronchopneumonia. In some cases it may be relatively symptomless, like other virus pneumonias, and pass unnoticed by parents. The original inflammation is probably multifocal, and normally clears up without any residual damage, but in bronchi which are inadequately drained of secretions the permanent changes of follicular bronchiectasis may arise.

\section{SACCULAR BRONCHIECTASIS}

"Saccular" is an apt word because it fits both the anatomical and the bronchographic appearance, though many specimens which did not show this

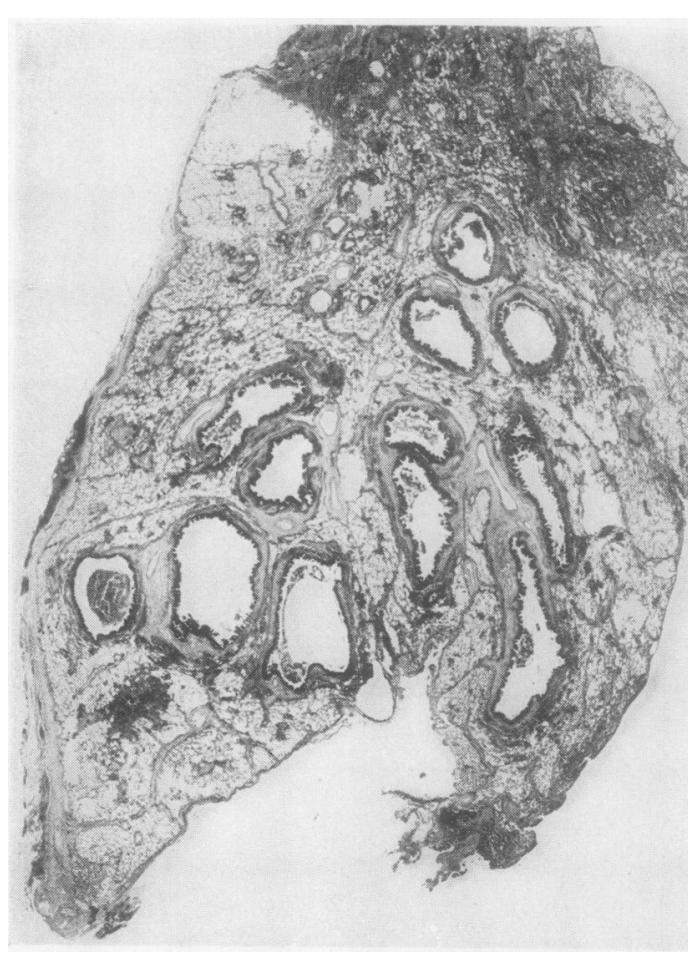

FIG. 23.-Saccular bronchiectasis of right lower lobe $4 \mathrm{~cm}$. from hilum (Case 395). Haematoxylin and eosin $\times 1.5$.

type of pathology could have been described $\stackrel{\overrightarrow{0}}{\not s}$ saccular from the bronchograms.

Twenty-three examples of this condition occurred in the present series. Two of them will be describet in some detail, and the pathology, clinical features, and pathogenesis of saccular bronchiectasis will ge di cussed.

CASE 395.-A 33-year-old woman, previously health apart from bad head colds, had suffered from a troubRsome cough for three years, and her symptoms hä become more severe recently. Her sputum was copio@, purulent, and occasionally blood-stained. She had finger clubbing and was dyspnoeic on slight exertion. Bronchograms showed bronchiectasis limited to the right middle and lower lobes. Right lower lobectoray was performed.

Macroscopic Appearance of Specimen.-The specimen is an aerated, pigmented lobe with pleural thickenigg over the apical and diaphragmatic surfaces.

On section (Figs. 22 and 23) the apical segment shors some collapse, emphysema, and interstitial pneumor(fa but the bronchi appear normal. The base of the lobe shows gross bronchiectasis, with the main bronchi dif normal calibre, though slightly thickened and occluded by folds of hypertrophic epithelium, while more pegpheral bronchi form pus-filled cavities. These sacculos are surrounded by aerated alveoli, and there is fibrous thickening of the interlobular septa. 
Microscopic Features.-The lesion in the apical segment appearing like pneumonia is a tuberculous infiltration, but there is no bronchial disease in this segment. No tuberculosis is to be found in the bronchiectatic basal segments, and the two conditions are thought to be unrelated.

Most striking is the polypoid appearance of the epithelial lining of the basal main bronchi, but because of tissue shrinkage during processing this is less conspicuous than in the untouched specimen. The bronchi are partly occluded by these polyps, which consist of vascular granulation tissue covered by columnar epithelium, the granulation tissue being part of a diffuse inflammatory reaction in the bronchial sub-epithelial tissues. In spite of this bronchial inflammation there is little loss of elastic tissue or muscle in the bronchial walls, and there is no loss of cartilage.

Each basal segmental bronchus divides into two or four branches which, after a short course, terminate in blind bulbous cavities, or saccules. While the presaccular bronchi all show similar microscopic features, an abrupt change is seen as they enter the saccules.

The saccules are large, irregular, somewhat flattened cavities containing pus; most of them are globular or

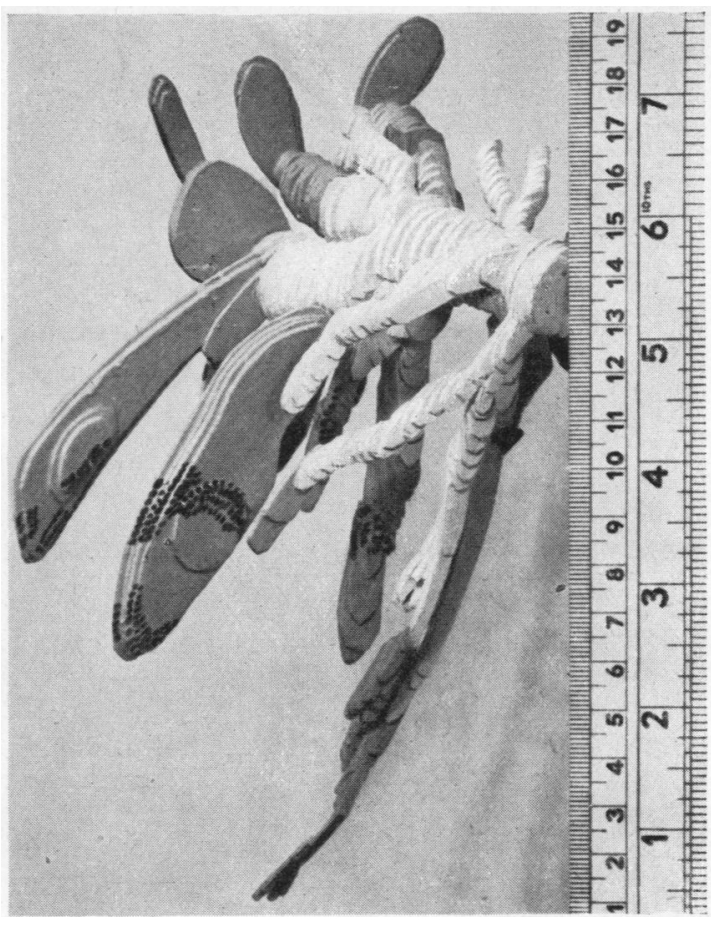

Fig. 24.-Model of basal segmental bronchi of lower lobe (Case 395).

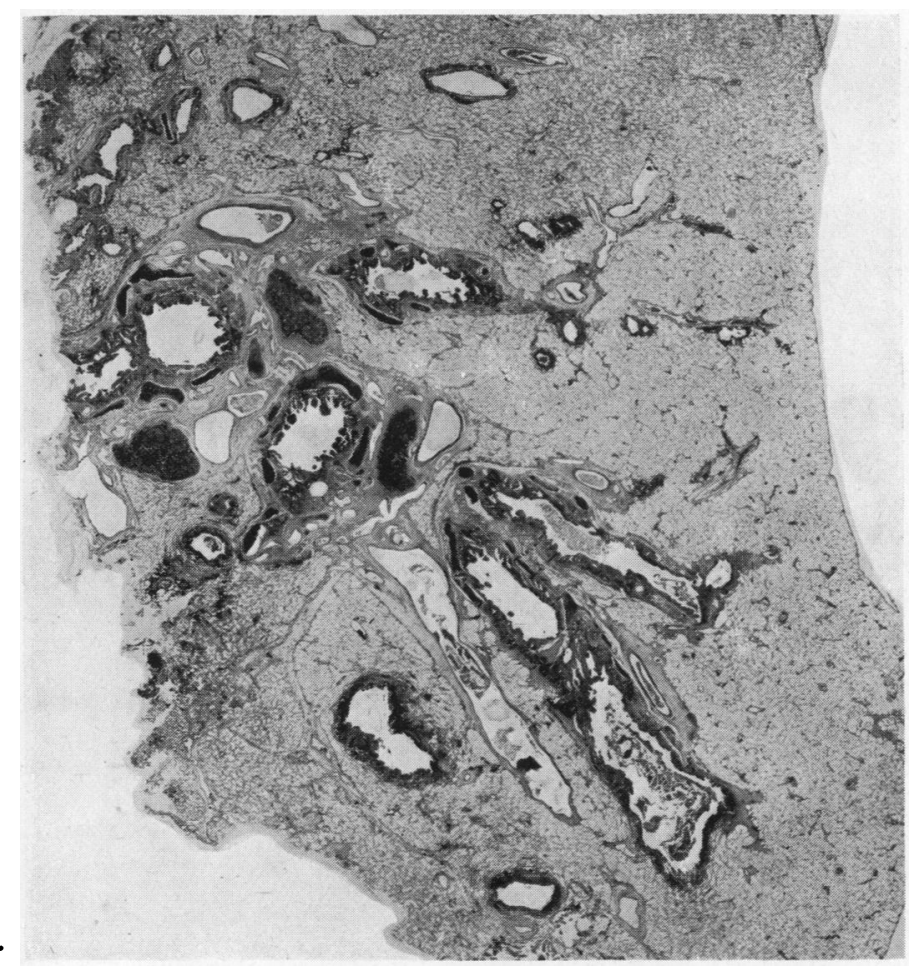

Fig. 25.-Saccular bronchiectasis in left lower lobe $2 \mathrm{~cm}$. from hilum (Case 451 ). Haematoxylin and eosin $\times 1.5$. elliptical, but some have an hour-glass shape.

Their epithelial lining is continuous, except for a few small erosions, and is composed mainly of cuboidal cells. Areas of squamous metaplasia are to be found in nearly all the saccules, chiefly at their bases, but also at places where opposing epithelial surfaces are almost in contact.

Dilated capillaries and chronic inflammatory cells lie beneath the epithelium, and the saccular walls consist of dense fibrous tissue which contains no elastic tissue, muscle, or cartilage.

The saccules represent terminations of the existing bronchial tree in the diseased segments; all more peripheral branches are either destroyed beyond recognition, or they are replaced by fibrous bands containing isolated fragments of cartilage and epithelium-lined cysts.

The gross features of this specimen can be seen in the model (Fig. 24), which has been reconstructed from sections taken $250 \mu$ apart. Parts of the bronchial tree which contain cartilage are represented in white, non-cartilaginous portions are grey, and areas with squamous metaplasia are shown by black dots.

Alveoli around the saccules, and in the basal segments generally, are well aerated. There are no severe inflammatory changes, but the lobular pattern of alveoli is made 


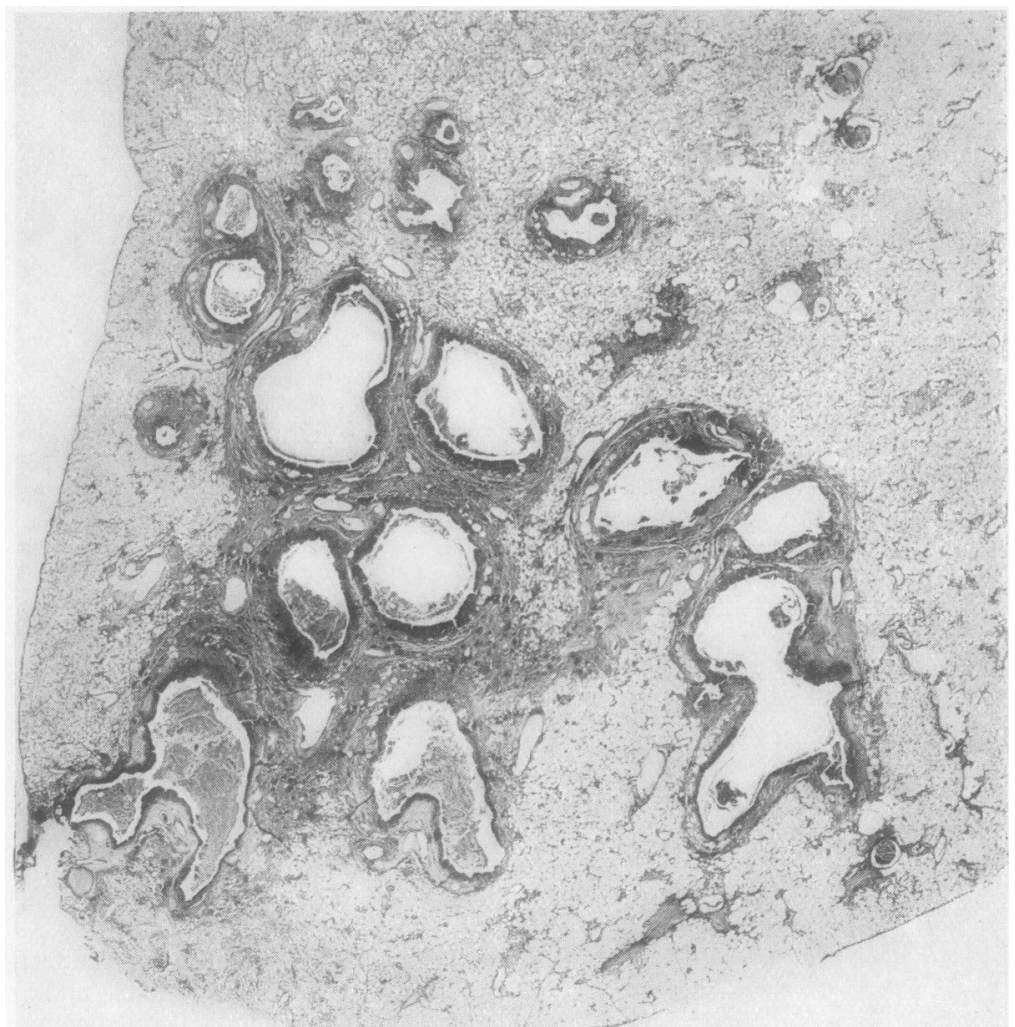

Fig. 26.-Saccular bronchiectasis $5 \mathrm{~cm}$. from hilum (Case 451). Haematoxylin and eosin $\times 1.5$.
The pre-saccular bronebi show marked polypoid changess in the epithelium. In Fig. F polyposis of the basal segment bronchi can be compared wifh the smooth epithelial lining क्ठै the normal apical bronchus.

The epithelial lining of the saccules is flatter than in the previous specimen, and areas of squamous metaplasia are mo extensive. No connexion wàs found between the saccules apd any distal bronchial tree-ib fact no intact distal bronchi $\overrightarrow{\mathrm{JJ}^{\mathrm{S}}}$ present, though respiratory broochioles occur in the parenchyma

The base of the lobe is wefl aerated except for a narrow zome of collapse around and betweeg the saccules. In the areas of celapse the alveoli are flattened cofcentrically around the saccules.-

There is no inflammato $\vec{g}$ reaction in the parenchyma, an only within the peribronchial, perisaccular, and interlobular septa is an increase of fibro tissue to be found.

The Pathology of Saccul BRONCHIECTASIS

These two examples are thought to be the end-resīt

conspicuous by thickening of interlobular fibrous septa. Within these lobules there are some respiratory bronchioles, but terminal bronchioles are replaced by fibrous scars.

CASE 451.-An 18-year-old boy was admitted to hospital because of a troublesome cough and a single slight haemoptysis. Bronchitis had occurred during the previous four winters, but there was no history of earlier respiratory complaint or infectious diseases. He produced $3 \mathrm{oz}$. of purulent sputum daily, had marked finger clubbing, and bronchograms showed bronchiectasis limited to the left lower lobe. This lobe was excised.

Macroscopic Appearance of Specimen.-The lobe is bulky, aerated, slightly pigmented, and has a shiny pleural membrane.

Sections of the lobe (Figs. 25 and 26) show a normal apical segment but severe bronchiectasis in the whole of the base. The segmental basal bronchi and their main branches are not thickened or dilated, but they are partially occluded by epithelial "polyposis"; more distal bronchi are saccular and filled with pus. The alveoli of the basal segments are aerated, except immediately around the saccules where there is some collapse.

Microscopic Features.-There is obvious similarity to the previous case, and only points of difference will be stressed.
- of a distinctive type of bronchiectasis. Although only $17 \%$ of specimens show these lesion, some of the unclassified lobes are probably earlier stages of the same condition. Characteristic saccules, normality of the alveoli around the bronchi, which retain normal supporting tissues. The saccules and the pre-saccular bronchi can be considered separately, the former being regarded the primary abnormality.

SACCULES.-Saccules are essentially fibrous strifgetures lined by a cuboidal epithelium; they have po elastic tissue, muscle or cartilage in their walls, afd their lining membranes contain no normal ciliated respiratory epithelium. This absence of recognizable tissues in the saccules has led to speculation about their origin and this subject will be discussefd later.

The constant finding of areas of squamolis metaplasia in the saccular epithelium is of spegfal interest as this phenomenon is uncommon in âpy of the other types of bronchiectasis examined. The usual distribution of this metaplasia is shown in features are gross loss of bronchial structures in the saccules, and "polyposis" of the pre-saccuar 
two examples (Figs. 24 and 27); sometimes it is less extensive, but in a few specimens the whole saccular lining is replaced by squamous epithelium extending for some distance up the pre-saccular bronchi.

Squamous metaplasia is mentioned in most accounts of bronchiectasis in the literature, but its distribution in the diseased lobes has rarely been described. From published illustrations it is clear that the term has been applied indiscriminately to various epithelial patterns, such as the layers of heaped-up, flattened cells that restore breaches of epithelial continuity, and the transitional epithelial appearance seen in obliquely sectioned bronchi (Engel, 1947). In the present account the term is used only when prickle cells or keratinization have been seen; the latter is extremely rare and was found only in three specimens.

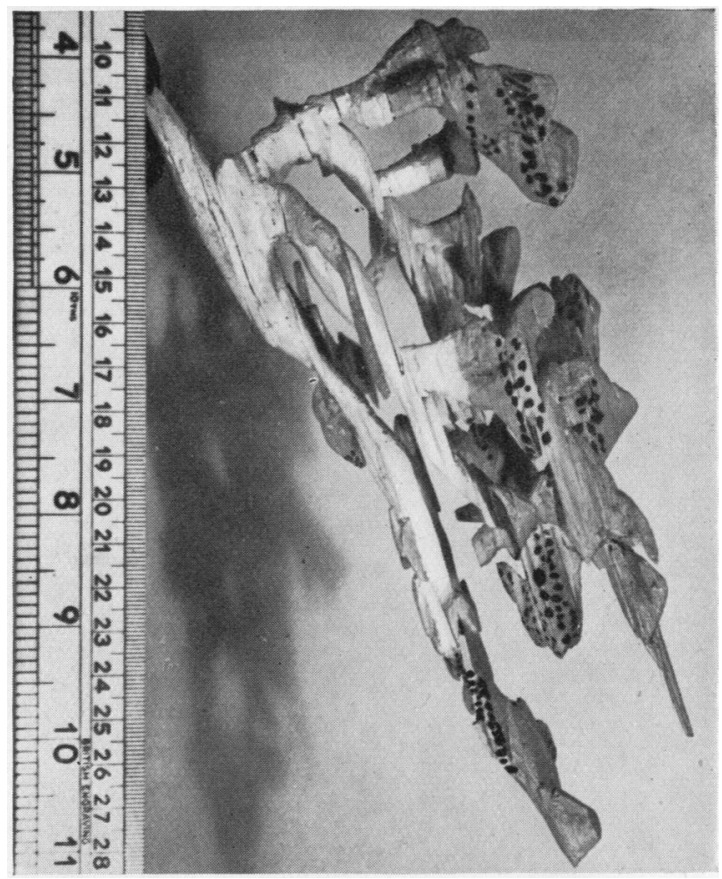

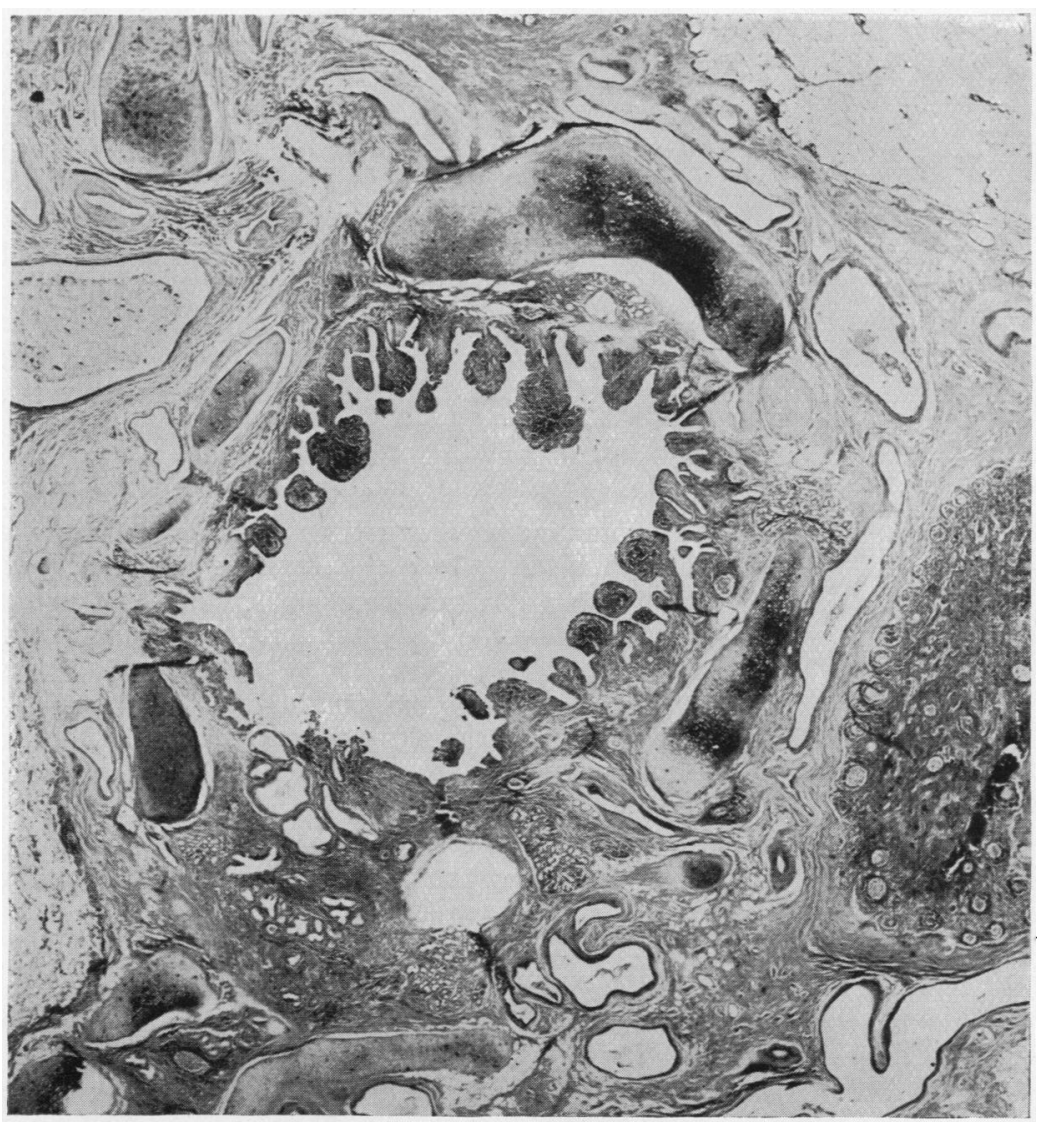

Fig. 28.-Polyposis of pre-saccular bronchi (Case 451). Haematoxylin and eosin $\times$ 7.5. bronchiectasis).

Robinson (1933, 1939) described squamous metaplasia of the proximal bronchi in a specimen of bronchiectasis, and he thought that it might have been a factor in the production of the disease by creating a physiological block of bronchial ciliary action. No such distribution was seen in the present specimens, in which the metaplasia was always at the distal end of the bronchial tree. In discussing this subject Willis (1948) says :

" Although it has often been stated that squamous change commonly occurs in chronic bronchiectasis and bronchitis, this is an error; except in carcinoma squamous metaplasia in human bronchial disease is rare."

However, metaplasia has been seen in all specimens of saccular bronchiectasis (which form $17 \%$ of the present series) as well as in several of the unclassified adult specimens, and bronchiectasis is almost as common as pul- 


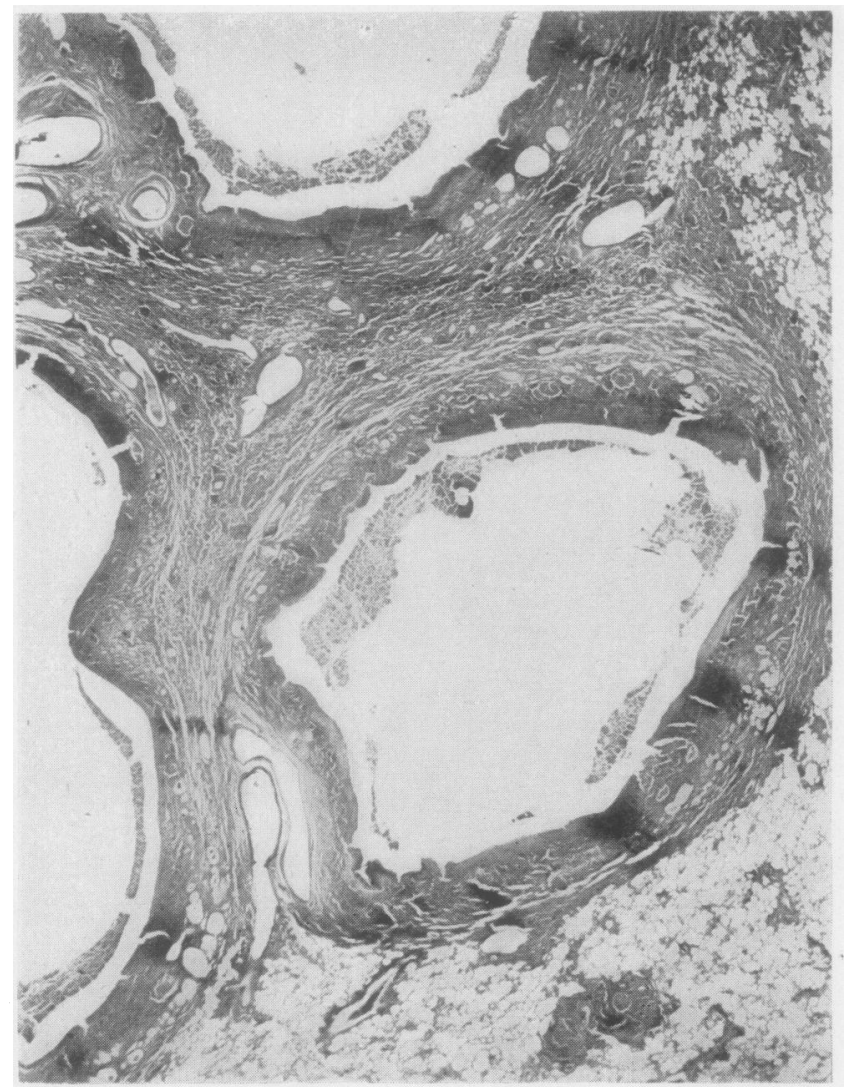

FIG. 29.-Saccules surrounded by rims of compression collapse (Case 451). Haematoxylin and eosin $\times 7.5$.

monary tuberculosis; Willis's statement cannot therefore be accepted.

The Pre-SaCCUlar Bronchi.-No dilatation occurs in the bronchi and there is little destruction of supporting tissues, despite the severe inflammatory reaction in the bronchial walls. The main abnormality is polyposis of the bronchial epithelium, often extensive enough to produce considerable bronchial obstruction.

In the present material this change has been seen only in saccular bronchiectasis, but similar lesions are to be found in the bronchi draining chronic lung abscesses and secondarily infected tuberculous cavities.

The bronchoscopic and histological features of this polypoid change have been described by Jackson and Jackson (1932), who thought that it was an inflammatory reaction produced by continual irritation from pus, an opinion supported by the present study. Peroni (1934) considered that the polyps occurred first, and then produced bronchiectasis by obstruction. Samsen (1940) described a severe case and though $\mathrm{t}$ the cause was an individual susceptibilivy to mucin. Many accounts of the patholo y of bronchiectasis mention the hypertrophifc bronchial epithelium, but the site affd association with saccules have not been stressed.

Collateral Air Circulation $\vec{\Phi}_{\mathbb{N}}$ Diseased SEgments. - The observation th all bronchi in the diseased segments end in blind saccules, and that these segmeries are well aerated, is considered to be $\mathcal{O} f \mathrm{f}$ some importance. It provides histologiç్gl confirmation of the existence of a collateral air circulation in bronchiectasis, which challenges the validity of certain popugr theories of pathogenesis.

Collateral air circulation was origina售y a theoretical conception based upon Фa belief in the existence of alveolar pores. Later this theory was tested and confirmed by animal experiments (Van Allen and Jung, 1931), and more recently by Baarsroa and Dirken (1948) using healthy rabbits, and by Baarsma, Dirken, and Huizinga (1948) in normal human lungs. These workers considered that a collateral $\mathbb{a}$ circulation occurred only in the absence $\overrightarrow{\mathbb{Q}} f$ inflammatory change in the obstructed segments.

The importance of this mechanism $\overline{\mathrm{F}}$ diseased lungs has only recently received any attention. Churchill (1949), describing the radiological appearances of isolated bronchiectatic lobes in which the bronchi had been filled with lipiodol, mentioned dilated bronchi extending into air-containing parenchyma but in no way commu国cating with it. These segments contained trappesd air, as they did not deflate when the lobes wefe removed from the body and left the bronchi open. This trapped air serves the function of filling iㅛ space but it has no oxygenating value.

In the two examples of saccular bronchiectasis the air must have reached the basal parenchyna through the normal apical segments. This suggests that the intersegmental and interlobular fibroषs septa are really incomplete fibrous networks which offer no barrier to air. Alveolar pores have bewn seen in the aerated alveoli of most specimens whenever sought in thick sections (Fig. 31).

Although collateral air circulation is most eas $\mathrm{Q} y$ demonstrated in the saccular cases, it occurs $\stackrel{\mathbb{o}}{\mathbb{1}}$ most forms of bronchiectasis which do not invole entire lobes. 
Clinical Features of Saccular Bronchiectasis

The age distribution of all these patients is shown in Fig. 4. Sixteen case-records were available for analysis, and the details are tabulated.

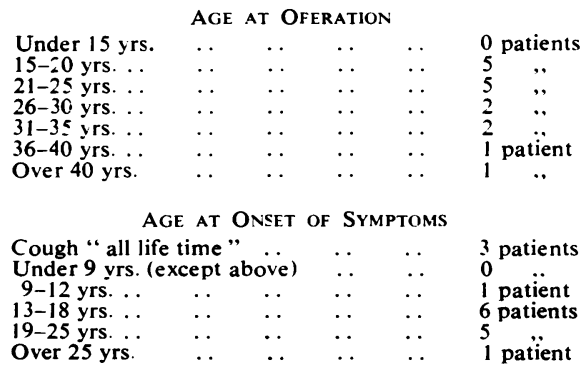
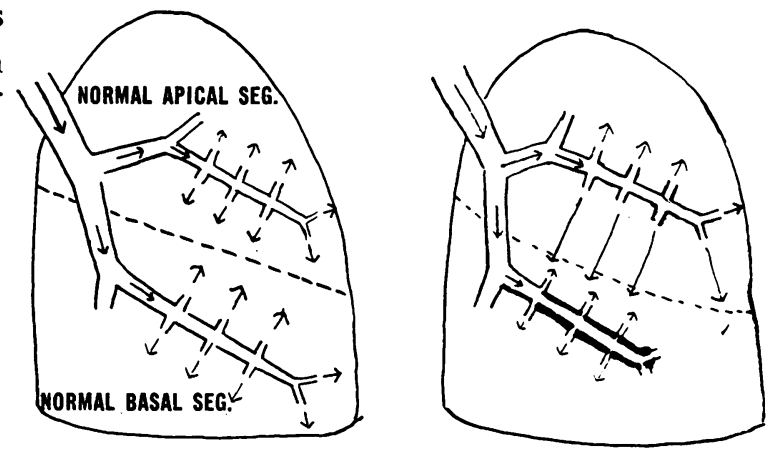

Pre-operative Duration of Symptoms

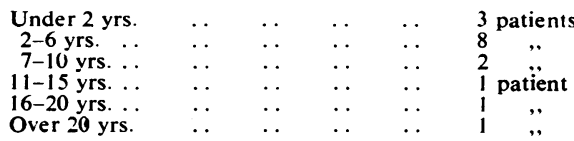

NATURE OF Illness at ONSET-OF Symptoms Measles and/or whooping cough $\quad$. $\quad 0$ patients

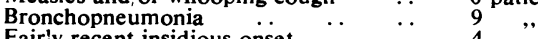

Fairly recent insidious onset 4 ,

Cough all life but no severe childhood 3

\begin{tabular}{|c|c|c|c|c|c|}
\hline \multicolumn{6}{|c|}{ Finger Clubbing } \\
\hline Present & . & . . & .. & . & 10 patients \\
\hline Doubtful & . & . & . & . & $2 \quad \cdots$ \\
\hline Absent $\quad$. & $\cdots$ & . & . & . & ". \\
\hline Not recorded & . & . & .. & . & , \\
\hline
\end{tabular}

Paranasal Sinus Infections

\begin{tabular}{|c|c|c|c|c|}
\hline & ${ }^{2}$ & (n) & 年 & \\
\hline sent . & $\cdots$ & $\cdots$ & $\cdots$ & 9 patients \\
\hline Doubtful & & & $\cdots$ & $2 \quad$, \\
\hline Absent & $\cdots$ & . & $\cdots$ & , \\
\hline Not recorded & $\cdots$ & . & $\cdots$ & 2 \\
\hline
\end{tabular}
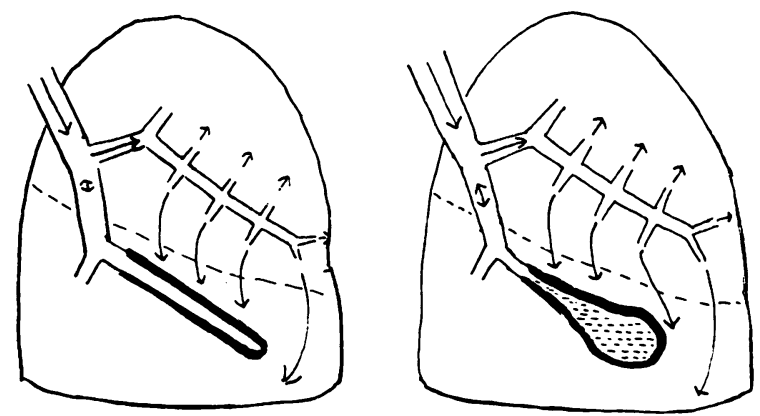

FiG. 30.-Development of collateral air circulation in saccular

All patients had copious purulent sputum.

No correlation was found between the extent, severity, and duration of the disease, and the presence of finger clubbing.

It is impossible to correlate the

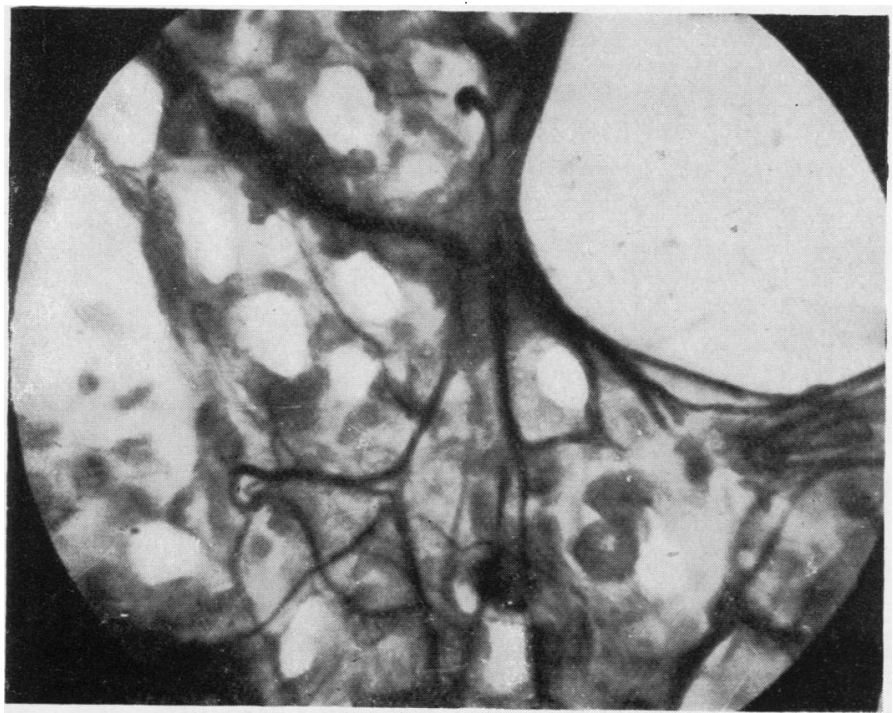
degree of polyposis and squamous metaplasia to the duration of illness.

\section{Pathogenesis of Saccular BRONCHIECTASIS}

As the changes in pre-saccular bronchi are considered secondary to the saccular lesions any discussion on pathogenesis amounts to the question, "From what and how do the saccules arise?"

SITE OF THE SACCules. - Writers have variously suggested that the dilatations of bronchiectasis originate from the bronchi (Robinson, 1933; Ogilvie, 1941 ; Mallory, 1947), the bronchioles (Lander and Davidson, 1938), and the parenchyma (Opie, 1928; Erb, 1933; McNeil, Macgregor, and Alexander, 1929; Lisa and Rosenblatt, 1943). 
Neoprene casts, reconstruction models, and dissections of the bronchial tree show that saccules are the bulbous terminations of the first to third branchings of the segmental bronchi. As adult bronchioles arise only after about 18 branchings from the segmental bronchi (Broman, 1923; Reid, 1950), the saccules clearly cannot be of bronchiolar origin.

Saccules are the direct continuations of large bronchi, they are encased within extension of the peribronchial fibrous septa, and they are placed close to and parallel with branches of pulmonary arteries. Their situation suggests that they were originally bronch:, and not bronchopulmonary excavations.

Cause of Dilatation.-First, it is possible to eliminate certain of the factors that are often suggested as causes of dilatation. Alveolar collapse is negligible in these specimens and cannot be considered as a possible cause, in spite of absolute peripheral bronchial obstruction. Fibrous tissue found in the saccular walls occurs only as a replacement of original bronchial structures. This fibrosis is concentric with the saccules, and not in a plane where, by contracting, it could exert any dilating force on the bronchi. Most writers link together fibrosis and contraction, especially when discussing bronchiectasis. However, the behaviour of fibrous tissue is perverse, and many examples occur of its property of ungoverned stretching, e.g., aortic aneurysms and in repaired hernias. Probably the stretching of fibrous tissue in saccular walls is a factor in the production of dilatation.

The clinical findings of this group of patients show that while in many cases the bronchiectasis dated from an attack of bronchopneumonia, in nearly half the patients the disease had an insidious onset which escaped notice.

It is considered that saccular bronchiectasis begins as a chronic mural inflammation of the medium-sized bronchi. This condition destroys bronchial wall structures and obliterates peripheral branches (Fig. 30), but is not sufficiently acute or diffuse to produce parenchymal scarring or to interfere with the establishment of a collateral air. circulation, provided all segments of a lobe are not affected.

The saccular shape of the diseased bronchi is probably produced after the destruction of supporting tissues and occlusion of peripheral branches, and results from distension by contained pus, the pressure of which is increased by the partial occlusion of pre-saccular bronchi (see Fig. 28). Support is lent to this theory by the compression-collapse seen in several specimens in perisaccular alvemli (Fig. 29) suggesting that an expansile forceois centred within the saccules.

The theory that dilatation is produced thro $\mathbb{B}_{\mathrm{gh}}$ distension of the bronchi by pus was originally fut forward by Laennec, but only a few (Riviere, 1905) have shared his opinion. As early as 1838 Williams discredited Laennec's theory by arguing that mgst patients with copious sputum do not deverop dilatation, and many patients with bronchiect䧹is have little sputum. Williams's argument was fălse because it did not take into account the condititen of the bronchial walls. Andrus (1937) discussed this subject and said:

"As a problem in physics it is sufficient to note at this time that in order to exert a dilating forcesit would be necessary that the secretion occupy the gefss section of the lumen of the bronchus; such a condition would, however, necessarily result in atelectasis, and its possible effects be indistinguishable from latter."

His theoretical aerodynamics did not allow $\overrightarrow{8}$ collateral air circulation, and the illustrated examples. do not support his statement.

\section{ATELECTATIC BRONCHIECTASIS}

In recent years there have been many accoums of the association of lobar and segmental collap̧se with bronchiectasis, and it has become widely accepted that the collapse leads to the bronchiectasis. In this condition, which has been cal atelectatic bronchiectasis (although it is recognized to be an acquired disease), the collapse is usuaply thought to be caused by peripheral bronchifal obstruction. Many writers have gone even furtiger and stated that all bronchiectasis, even when congenital, is caused in this way.

The specimens which have here been classified as follicular and saccular rarely showed collapse, even on microscopic examination; where collapse was found it appeared to be consequent to bronchiectasis. However, some others of ghe specimens did show severe alveolar collapse, so they have been examined as a group in an attengot to find out whether the collapse or the bronchiectasis. comes first, and how this condition arises.

ছৃ

The specimens lack homogeneity; in some bronchi are collapsed, in others there is gress. dilatation, and in most of them the bronchi are thickened but only moderately dilated (Fig. 37). However, the grouping has been of some vaghe because it has shown that "atelectatic bronchigetasis" differs from other forms of the disease an its lobar and segmental distribution, and in 再e 


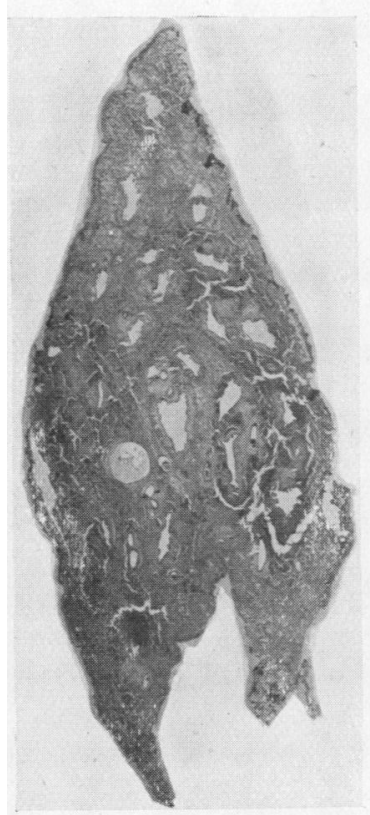

A

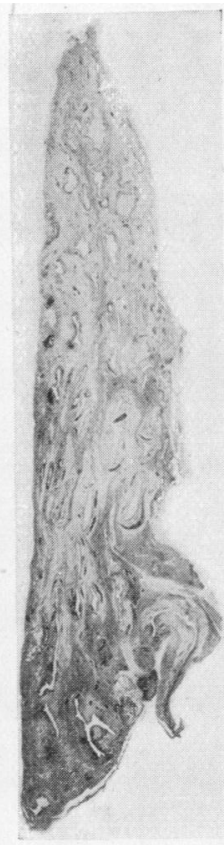

B

FIG. 32.-Atelectatic bronchiectasis of two lower lobes. Haematoxylin and eosin.

histology of the bronchi. Wide variations in the pathology of these specimens makes it impossible to give typical examples; the pathological findings, therefore, will be discussed under headings, and clinical features will be tabulated.

\section{PATHOLOGY}

INCIDENCE AND LOBAR DisTRIBUTION.-The group contains 21 specimens, about $10 \%$ of the whole series.

The lobes affected are as follows:

\begin{tabular}{|c|c|c|c|c|c|}
\hline R.M.L. - & + R.L.L. & $\cdots$ & $\cdots$ & $\cdots$ & 10 specimer \\
\hline $\begin{array}{l}\text { R.M.L. } \\
\text { R.L.L. }\end{array}$ & $\cdots$ & $\cdots$ & $\cdots$ & . & \\
\hline $\begin{array}{l}\text { R.L.L. } \\
\text { L.L.L. }\end{array}$ & $\cdots$ & $\cdots$ & $\cdots$ & $\cdots$ & 1 specimer \\
\hline Lingula & $\cdots$ & $\cdots$ & $\because$ & $\because$ & 1 specimen \\
\hline L. Lung & . & . & . & .. & $1 \quad$, \\
\hline
\end{tabular}

Middle lobes, and middle with lower lobes, represent $15 \%$ and $50 \%$ respectively of the collapsed specimens, though they form only $4 \%$ and $7 \%$ of specimens in the whole series. While right-sided specimens form only a quarter of the whole series, they represent three-quarters of the collapsed specimens.

Specimens consisting of middle with lower lobes do not always show atelectatic bronchiectasis in both lobes. The finding's are as follows.

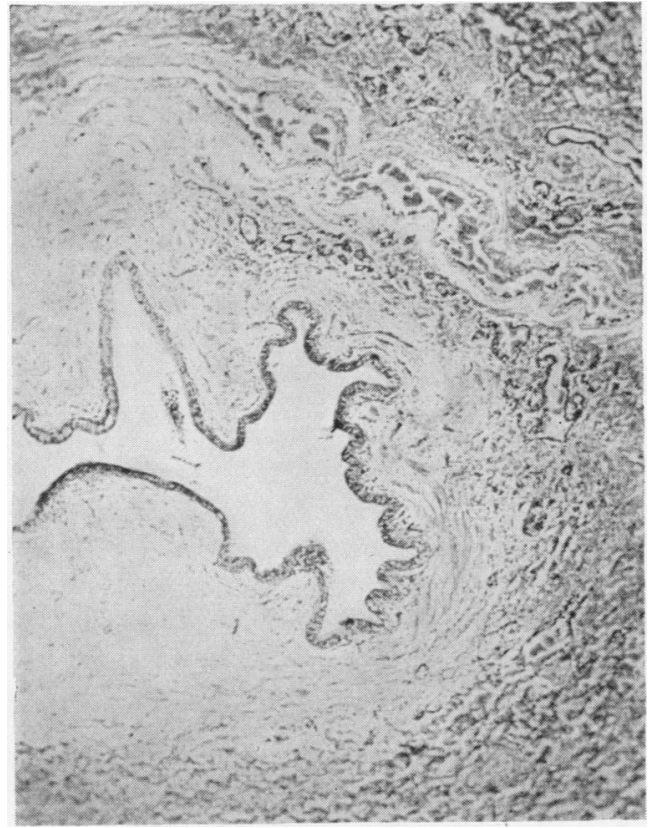

FIG. 33.-Atelectatic bronchiectasis with fibrous replacement of bronchial wall structures. Haematoxylin and eosin $\times 30$.

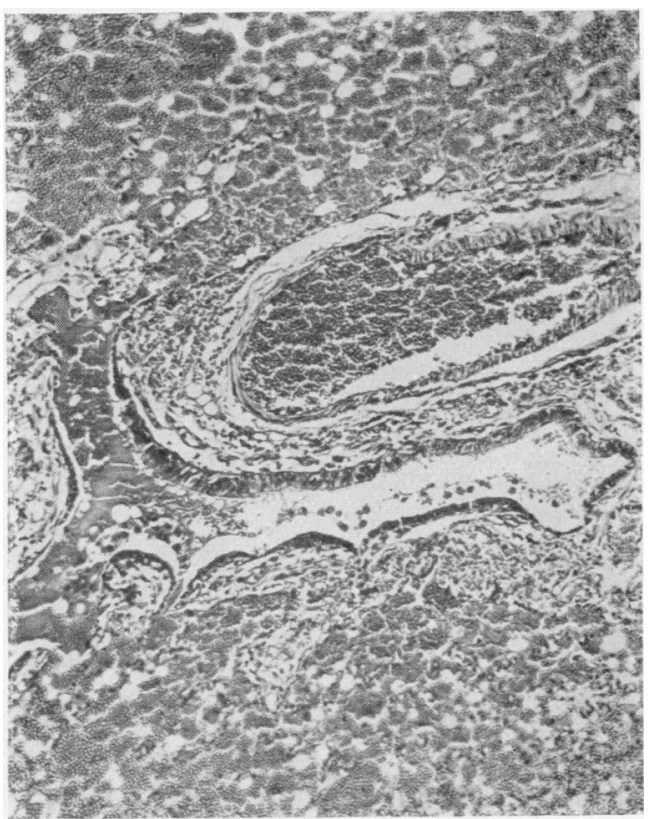

FIG. 34.-Atelectatic bronchiectasis with intra-bronchiolar and intra-alveolar haemorrhage with patent bronchioles. Haematoxylin and eosin $\times 90$. 


\begin{tabular}{l|l|c}
\hline \multicolumn{1}{c|}{ Middle Lobe } & \multicolumn{1}{|c}{ Lower Lobe } & $\begin{array}{c}\text { No. of } \\
\text { Specimens }\end{array}$ \\
\hline Collapse only & Atelectatic bronchiectasis & 2 \\
Atelectatic bronchiectasis & Collapse only & 1 \\
Atelectatic bronchiectasis & Atelectatic bronchiectasis & 3 \\
Atelectatic bronchiectasis & Saccular bronchiectasis & 1 \\
Collapse only & Follicular bronchiectasis & 1 \\
Atelectatic bronchiectasis & Follicular bronchiectasis & 1 \\
Collapse only & Unclassified bronchiectasis & 1 \\
\hline
\end{tabular}

SEgmental Distribution.-In all segments of an affected lobe the bronchi show similar histological changes. It is very difficult to assess calibre differences in collapsed specimens, but usually the degree of dilatation appeared about equal in each segment.

BronChIAL OBSTRUCTION.-The lobar bronchi have been examined for stenoses and other lesions that might cause bronchial obstruction. None is present in lobes showing bronchiectasis, but in specimens of simple collapse the bronchi are also collapsed - and therefore obstructed.

Sections have been examined microscopically for obstructing lesions of the peripheral bronchial tree. In contrast to follicular and saccular bronchiectasis, in which peripheral obstruction is invariable, the bronchioles are patent and can be followed into the pulmonary lobules, where the air cells are partly collapsed (Fig. 34).

Hilar Lymph-Gland Changes. - In many specimens the lymph-glands around the hilar bronchi are greatly enlarged, and on section showed nonspecific chronic lymphadenitis, often with fibrotic changes. These glands are indistinguishable from the hilar glands in follicular bronchiectasis.

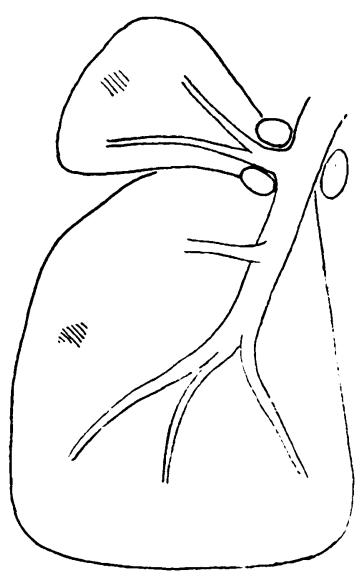

a
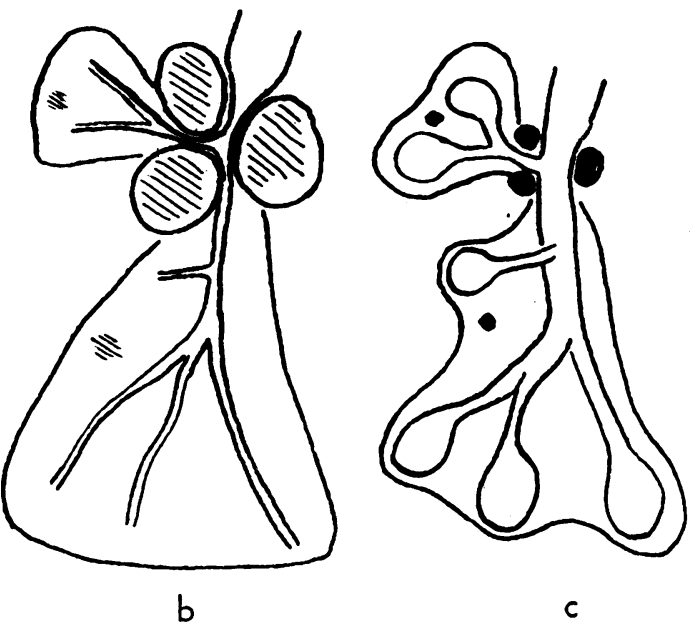

Fig. 35.-Development of ate tatic bronchiectasis (a) small focus in periphery of modxle and lower lobe; (b) enläged hilar glands and lobar oollapse; (c) atelectatic bronochiectasis with calcified foci in hilar glands. these specimens the hilar lymph-glands contain calcified caseous foci. Except for two specimens $\rho$ f tuberculous bronchiectasis and a saccular breुhchiectasis with tuberculosis in the non-bronchec-

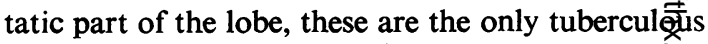
lesions seen in the whole series.

Bronchial TREe.- The bronchi in collaps్s specimens show similar histology throughout a lobe. There may be (1) moderate inflammation without any destruction of supporting tissue This was also always seen in specimens of simple collapse. (2) Slight superficial inflammation, But bronchial walls show dense fibrous thickening, $\overrightarrow{\text { ind }}$ contain no elastic tissue, muscle, or cartilugge (Fig. 33). (3) Severe inflammatory changes with epithelial ulcerations and destruction of supportiditg tissues.

severely affected. In some specimens inflareed bronchial walls contain numerous lymph follicfes, but interstitial pneumonia is absent.

The type of histological change in the brorothi appears to be unrelated to the degree of dilatation.

AlVEOLI.-In spite of the gross reduction in of the lobes, and the apparent total alveolar collapse, the microscopic appearances are usuffly those of incomplete absorption collapse.

Many lobes seem to be infarcted; in these there is extravasation of red cells into interstitial tissues, and the partly collapsed alveoli, and some brônchioles, are distended with blood (Fig. 34). M.st 
of this haemorrhage consists of fresh red cells, but deposits of haemosiderin in cells of the alveolar walls and in intra-alveolar heart-failure cells shows that some bleeding must have occurred before operation. This intra-alveolar haemorrhage was rarely seen in other forms of bronchiectasis. The operative technique was similar in all cases.

In the lobes showing simple collapse elastic tissue in alveolar walls appears to be thickened, probably because of its relaxed state. In atelectatic bronchiectasis the alveolar wall elastic tissue is either represented by a few short thick curls, or it is completely absent. A variable amount of inter-alveolar fibrosis is seen but there are no other signs of inflammation.

\section{Clinical Features of Atelectatic BRONCHIECTASIS}

The age distribution of all cases is shown in Fig. 4. The case-records of 15 patients were available for analysis, and provided the following details.

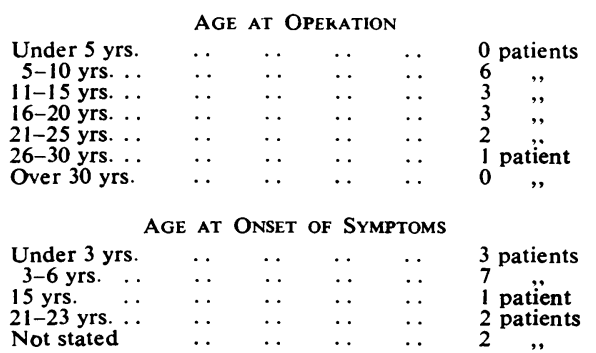

Pre-operative Duration of Symptoms

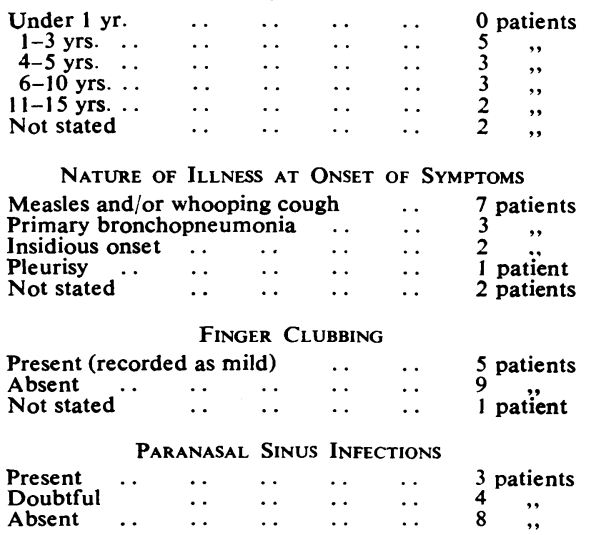

Three patients who had tuberculous foci in the lobes and hilar lymph-glands dated their symptoms from whooping-cough or measles in early childhood.

There was a close correlation between the amount of inflammatory change seen in the bronchi and the quantity and nature of the sputa; in many cases there was a complete absence of sputum.

\section{Pathogenesis of Atelectatic Bronchiectasis}

The following features, which are characteristic of atelectatic bronchiectasis and not of other forms of the disease, suggest how atelectatic bronchiectasis may arise: (1) the generalized distribution of collapse and bronchiectasis in the lobes; (2) the absence of central or peripheral bronchial obstruction in the lobes at the time of operation; (3) the presence of tuberculous foci in some lobes and hilar lymph-glands; (4) the frequency of involvement of the right middle lobe, either alone or with the lower lobe; (5) the variability of bronchial changes, and the absence of inflammation in the collapsed parenchyma; (6) the absence of finger clubbing, sinus infections, and foul sputum in many patients.

The bronchiectasis must either be the cause, or the result, of collapse. If collapse were secondary to bronchiectasis one would expect the segmental distribution of the lesions, and their histology, to be the same as in aerated forms of the disease. This was not so, so the collapse is probably the primary condition. There were a few exceptions to this generalization; they may have been secondarily-collapsed follicular bronchiectases.

If the theory that collapse is caused by peripheral bronchial obstruction is accepted, in these cases one is forced to conclude that simultaneous obstructions occurred in all peripheral bronchi; otherwise the bronchiectasis could not affect all branches, and collateral air circulation would prevent alveolar collapse. The improbability of such an occurrence, and the complete absence of peripheral obstruction i. 2 most of the specimens, suggests that there is no sound basis for this theory.

There is far more evidence supporting the view that collapse is caused by obstruction of lobar bronchi. Although no obstructive lesions of the proximal bronchi were found in these specimens, or seen in pre-operative bronchograms, the frequent finding of enlarged, fibrotic, or caseous hilar lymphglands suggests that collapse arose from occlusion by these glands of the lobar bronchi. This theory receives further support from the high incidence of right middle lobe specimens in atelectatic bronchiectasis, for Brock (1946) has demonstrated the peculiar vulnerability of the middle lobe bronchus to compression from enlargement of the surrounding lymph glands.

Recently Brock (1950) has described suppurative changes, bronchiectasis, and collapse in middle lobes as a sequel to tuberculous hilar adenitis. $\mathrm{He}$ 
states that in some cases this glandular enlargement may be non-tuberculous, and that similar changes may occur in other lobes. Specimens in this group were not examined for calcified foci radiologically, but they were dissected carefully and all hilar lymph glands were examined.

Some specimens in this group showed absorption collapse without bronchiectasis. In these lobes the bronchi were collapsed with their walls in apposition, and no irreversible histological changes were present, either in the bronchi or alveoli.

It is thought that this is similar to the state of a lobe when its hilar bronchus had been occluded by lymph gland enlargement. When these glands shrink the lobar bronchus becomes patent and air can again enter the bronchial tree. In many cases this is followed by aeration of the collapsed alveoli and the restoration of the lobe to normal, but if severe inflammatory changes have occurred in the bronchi, or if fibrosis has taken place in the parenchyma, the lobe is unable to expand again. In such a case (Fig. 35), permanently collapsed alveoli surround aerated bronchi, which dilate because of destruction of their supporting tissues and accumulation of bronchial secretions. The slight reduction in intra-pleural pressure, which might occur after collapse of a middle lobe, could exert little dilating force on its bronchi.

Bronchial dilatation in these cases may be explained on mechanical grounds without the necessity of there being severe inflammatory changes, though the initial cause of the hilar lymphadenopathy is usually inflammatory. The absence of finger clubbing, sinus infections, and purulent sputum in many of this group of patients supports this theory of a mechanical disorder.

\section{DISCUSSION}

Although in this investigation a great variety of bronchiectatic lesions has been found, the account has been limited to a.description of three common forms which were seen in operation specimens. In no instance could the bronchial dilatation have been considered to be reversible; it was always the - result of destructive inflammatory processes, permanent alveolar collapse, or abnormal development resulting in bronchi of wide calibre.

Follicular and saccular bronchiectasis have distinctive lesions and natural histories. Atelectatic bronchiectasis is a less specific and largely a mechanical disorder, which usually follows occlusion by hilar adenitis of a lobar brorchus. The causes of lymphadenopathy are not restricted to any period of life, neither are the specimens from patients of any particular age, though they age mostly from young children. It is natural that the hilar adenitis seen in follicular bronchiectases should, in some instances, produce total obstruction of lobar bronchi, and result in specimens whigh show a mixture of follicular and atelectatic lesions.

All these lesions have been described previously on many occasions, but in the literature they hare usually been regarded as variations in a sing: disease entity. It is not intended to review th literature; excellent summaries can be found in the works of Ewart (1900), Ballon, Singer, and Graham (1931), Ogilvie (1941), and Lisa and Rosenblatt (1943). It is sufficient to remark that only three accounts appear to be inconsistent with the present study. Lander and Davidson (1938) reporting on 140 operation specimens, found litt destruction of bronchial wall structures, and many cases only slight indications of inflammatio Specimens such as these were extremely rare in the present series; they were not considered to be truxe bronchiectasis, and their removal had been dys to misinterpretation of radiological and clinical features. Lisa and Rosenblatt (1943), reporting oo 110 post-mortem specimens, remarked that th bronchial elastic tissues were relatively unimpaire In the present study one of the earliest and mo constant features of affected bronchi and bronchioles has been the destruction of elastic tissue. Moor $\overrightarrow{\vec{\theta}}$ Kobernick, and Wiglesworth (1949) have stated that there is little correlation between the bronch graphic appearances of a lobe and the condition of the bronchi; in fact, their work suggests th segmental resections can be of little value. The opposite conclusion has bcen reached from the present study.

Literature on the pathogenesis of bronchiectasis is even more voluminous than that on its pathologes and it is much more confusing. One reason is, perhaps, that many theories are based on pathology which is inferred rather than observed. For examples similar radiological appearances are described collapse, fibrosis, and pneumonia, by differengs writers who deduce that these various conditions are the cause of bronchiectasis. Another source of confusion is the vague use of the word "bror chiectasis." For example, it is used in describing some histological findings in fatal cases of pneumon (Opie, 1928; McNeil et al., 1929), the gross lesions produced in animals by experimental methods (Weinberg, 1937; Tannenberg and Pinner, 1942 and the temporary bronchographic changes found in $90 \%$ of university students who suffer from recurrent bronchitis (Ochsner, 1930). From studie in similar rather restricted fields many writers hare 
generalized about the pathogenesis of clinical bronchiectasis.

Fortunately, the number of theories of pathogenesis is limited; in fact, apart from the possible influence of allergy and sinus infections, no new theory has been propounded in the last hundred years. Nearly all writers are agreed that normal bronchi do not dilate when subjected to various mechanical stresses, and most theories accept a primary basis of bronchial weakness, due either to inflammation or developmental defects.

Developmental abnormalities and the most commonly suggested secondary causes of dilatation are discussed below.

\section{Developmental Abnormalities}

About $10 \%$ of the specimens were examples of congenital cystic lung, which is a developmental abnormality. In five other specimens the bronchi were thin-walled, and the calibre of the small branches was unduly wide, often, indeed, much wider than the proximal bronchi. No inflammatory, fibrotic, or destructive lesions were present, and the parenchyma was entirely normal. In three of these specimens, however, the bronchial supporting tissues seemed to be underdeveloped. The wide calibre appeared to be their natural condition and not due to dilatation.

Apart from these few specimens no evidence was found of any developmental abnormalities; nor was it necessary to postulate any such defects in order to explain the bronchiectasis.

\section{Pressure of Secretion In Bronchi}

This theory, and the objections to it, have been discussed on page 232. The terminal dilatations in saccular bronchiectasis probably result from distension of weakened bronchi by their contained secretions. The same mechanism may account for many of the dilatations of follicular and atelectatic bronchiectasis, though this is more difficult to substantiate.

\section{FIBROSIS}

The usual theory supposes that bronchi become dilated by the contraction of bands of fibrous tissue running between them, but no such arrangement of fibrous tissue was seen in the specimens. Fibrosis occurred as a thickening of the normal fibrous structures in the peribronchial, perivascular, interlobular, and pleural connective tissues. Occasionally concentric fibrosis was seen in the walls of diseased bronchi, and it was always present in the walls of saccules. Inter-alveolar fibrosis was Q found in some areas of chronic interstitial pneumonia, and in absorption collapse.

In most forms of bronchiectasis fibrosis is a late development. It is the stretching of fibrous bronchial walls in saccular bronchiectasis that leads to dilatation; it is the parenchymal fibrosis of atelectatic bronchiectasis which prevents re-aeration.

\section{BRONCHO-PULMONARY EXCAVATION}

In a few lobes the dilatations appeared to be re-epithelialized abscess cavities, which had originated in the parenchyma. However, these lesions were uncommon and not seen in the three types of bronchiectasis described.

\section{Peripheral Bronchial Obstruction and Alveolar Absorption Collapse}

These two lesions are linked in most recent discussion on pathogenesis (Warner and Graham, 1933; Boyd, 1935; Andrus, 1937, 1940; Lander and Davidson, 1938; Fleischner, 1940; Lander, 1946; Coope, 1948). It is argued that collapse follows obstruction, and dilatation occurs in bronchi proximal to the obstruction. These bronchi are subjected to a great dilating stress, which is caused by the difference in pressure between the pleural space and the atmosphere in the bronchi.

From the present study there appears to be no sound basis for this theory. Obstruction of peripheral bronchi was always present in follicular and saccular bronchiectasis, but absorption collapse was absent, probably because of adequate collateral air circulation. Absorption collapse was found in $10 \%$ of the specimens but it affected whole lobes, not lobules or segments. No peripheral bronchial or bronchiolar obstruction was present in these lobes, and the collapse had probably been caused by proximal bronchial obstruction.

Many other arguments can be raised against this theory. In cases where only a few small bronchi in one segment are affected there could be no significant alteration of pleural pressure to create a dilating force, even if collapse occurred distal to the bronchiectasis. The absence of radiological collapse in many cases has been explained in many unconvincing ways. Andrus (1940) states that patchy collapse is diagnosed as pneumonia, that collapse is concealed by the heart shadow, and that collapse may cause lung injury "and then be dissipated." Perry and King (1940) think that collapse can "lie dormant" for many years until purulent bronchitis supervenes. These reasons for the absence of radiological collapse, even if accepted, do not explain the normal aeration of so many 
TABLE III

Pathology OF Bronchiectasis

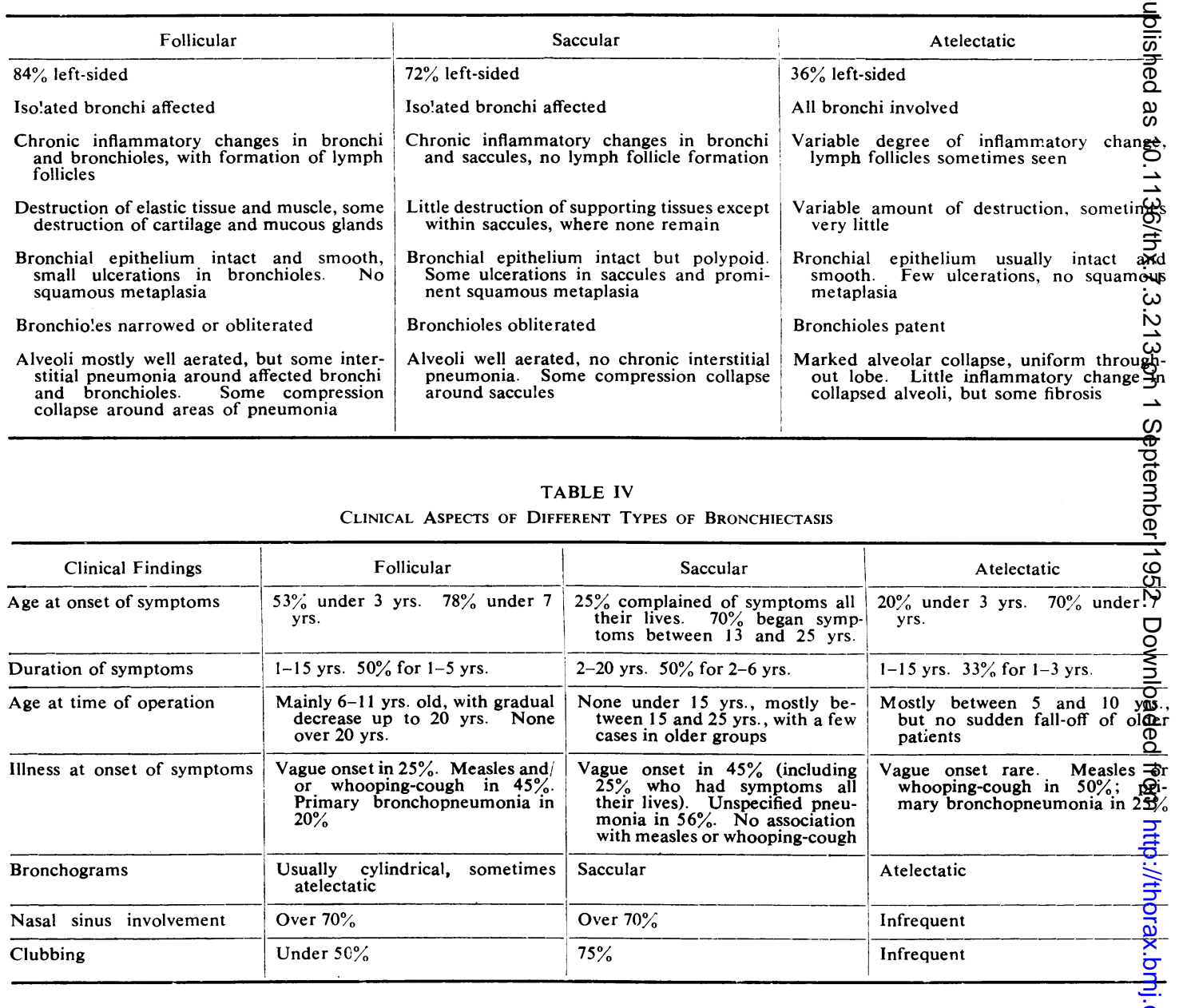

operation specimens, such as has been seen in the present series, and which has frequently been described in the literature.

\section{SUMMARY}

The investigation has consisted of the examination of 200 consecutively removed bronchiectatic lungs and lobes. Methods used consisted of neoprene injection casts of bronchial trees, large histological sections of entire lobes, and detailed dissections of bronchial trees with histological examinations of selected areas.

The lobar, segmental, and intra-segmental distribution of the lesions have been described (see Tables I and II, and Fig. 10).

More than half the specimens belonged to one or other of three rather distinctive types of bron- chiectasis, which have been called follicul@, saccular, and atelectatic bronchiectasis, and them pathology, clinical features, and pathogenesis higs been discussed (see Figs. 21, 30, and 35, atped Tables III and IV).

Finally, current theories of pathogenesis hanee been criticized in the light of the present enquiry:

This work has been only made possible through the co-operation of the staff of the Surgical Chest Cente, Broadgreen Hospital. In addition I would like to thank Mr. H. Morriston Davies, Mr. F. R. Edwards, and Ifr. Robert Coope for many valuable discussions on mediẹal and surgical aspects of bronchiectasis. I wish also to acknowledge my indebtedness to Dr. Rachel M. Ra@cliffe for her assistance in the preparation of neoprene casts and in the tabulation of case-records, and fo $_{0}$ Dr. P. J. Taylor for correction of the MS. 


\section{REFERENCES}

Allison, P. R., Gordon, J., and Zinnemann, K. (1943). J. Path. Bact., $55,465$.

Andrus, P. M. (1937). Amer. Rev. Tuberc., 36, 46.

- (1940). Ibid., 41, 87.

Baarsma, P. R., and Dirken, M. N. J. (1948). J. thorac. Surg., 17, 238.

and Huizinga, E. (1948). Ibid., 17, 252.

Ballon, H., Singer, J. J., and Graham, E. A. (1931). Ibid., 1, 154.

Boyd, G. L. (1935). J. Amer. med Ass., 105, 1832.

Brock, R. C. (1946). The Anatomy of the Bronchial Tree. London. - (1950). Thorax, 5, 5.

Broman, I. (1923). Anat. Anz., 57. Suppl. (Verh. anat. Ges.), p. 83. Quoted by Engel.

Churchill, E. D. (1949). J. thorac. Surg., 18, 279.

- and Belsey, R. (1939). Ann. Surg., 109, 481.

Coope, R. (1948). Diseases of the Chest, 2 nd ed. Edinburgh.

Cruikshank, A. H. (1948). J. Path. Bact., 60, 520.

Engel, S. (1947). The Child's Lung. London.

Erb, I. H. (1933). Arch. Path., 15, 357.

Ewart. W. (1900), Allbutt and Rolleston's System of Medicine, 2nd ed., vol. 5, p. 127 seq. London.

Fleischner, F. (1940). Amer. Rev. Tuberc., 42, 297.

Jackson, C., and Jackson, C. L. (1932). J. Amer med. Ass., 99, 1747.

Laennec, R. T. H. (1819). Dz L'Auscultation Médiate. Paris.

Lander, F. P. L. (1946). Thorax, 1, 198.

and Davidson, M. (1938). Brit. J. Radiol., 11, 65.

Lisa, J. R., and Rosenblatt, M. B. (1943). Bronchiectasis. London.

MacCallum, W. G. (1940). Textbook of Pathology, 7th ed. Philadelphia.
McNeil, C., Macgregor, A. R., and Alexander, W. A. (1929). Arch. Dis. Childh., 4, 170 .

Mallory, T. B. (1947). New Engl. J. Med., 237, 795.

Maximow, A. A.. and Bloom, W. (1942). Textbook of Histology, 4th ed. Philadelphia.

Miller, W. S. (1947). The Lung, 2nd ed. Springfield, Illinois.

Moore, J. R., Kobernick, S. D., and Wiglesworth, F. W. (1949). Surg. Gynec. Obstet., 89, 145.

Neison, J. B. (1946). J. exp. Med., 84, 7 and 15.

Ochsner, A. (1930). Amer. J. med. Sci., 179, 388.

Ogilvie, A. G. (1941). Arch. intern. Med., 68, 395.

Opie, E. L. (1928). Arch. Path., Chicago, 5, 285.

Overholt, R. H., Betts, R. H., and Woods, F. M. (1947). Dis. Chest, $13,583$.

Peroni, A. (1934). Arch. Otolaryng., 19, 1. Quoted by Samson

Perry, K. M. A., and King, D. S. (1940). Amer. Rev. Tuberc., 41, 531 .

Reid, L. McA. (1950). Thorax, 5, 233.

Riviere, C. (1905). St. Bart's Hosp. Rep., 41, 123.

Robinson, W. L. (1933). Brit. J. Surg., 21, 302.

(1939). Amer. J. Path., 15, 638.

Samson, P. C. (1940). J. thorac. Surg., 9, 679.

Schmidt, H. W. (1947). Ann. Otol., St. Louis, 56, 793.

Tannenberg, J., and Pinner, M. (1942). J. thorac. Surg., 11, 571.

Van Allen, C. M., and Jung, T. S. (1931). Ibid., 1, 3.

Warner, W. P., and Graham, D. (1933). Arch. intern. Med., 52, 888.

Watts, C. F., and McDonald, J. R. (1948). Arch. Path., Chicago,

Weinberg, J. (1937). J. thorac. Surg., 6, 402.

Williams, C. J. B. (1838). Lond. med. Gaz., n.s. 1, 913.

Willis, R. A. (1948). Pathology of Tumours. London. 